\title{
Applying UPC Scaling-Up Methodology to the LSTF-PKL Counterpart Test
}

\author{
V. Martinez-Quiroga, F. Reventos, and J. Freixa \\ Technical University of Catalonia, Institute of Energy Technologies, Avenida Diagonal 647, 08028 Barcelona, Spain \\ Correspondence should be addressed to V. Martinez-Quiroga; victor.martinez@nortuen.com
}

Received 2 September 2013; Accepted 12 December 2013; Published 2 March 2014

Academic Editor: Eugenijus Ušpuras

Copyright (C) 2014 V. Martinez-Quiroga et al. This is an open access article distributed under the Creative Commons Attribution License, which permits unrestricted use, distribution, and reproduction in any medium, provided the original work is properly cited.

In the framework of the nodalization qualification process and quality guarantee procedures and following the guidelines of $\mathrm{Kv}$-scaled analysis and UMAE methodology, further development has been performed by UPC team resulting in a scaling-up methodology. Such methodology has been applied in this paper for analyzing discrepancies that appear between the simulations of two counterpart tests. It allows the analysis of scaling-down criterion used for the design of an ITF and also the investigation of the differences of configuration between an ITF and a particular NPP. For analyzing both, it applies two concepts "scaled-up nodalizations" and "hybrid nodalizations." The result of this activity is the explanation of appeared distortions and its final goal is to qualify nodalizations for their use in the analysis of equivalent scenarios at an NPP scale. In this sense, the experimental data obtained in the OECD/NEA PKL-2 and ROSA-2 projects as counterpart test are of a great value for the testing of the present methodology. The results of the posttest calculations of LSTF-PKL counterpart tests have allowed the analyst to define which phenomena could be well reproduced by their nodalizations and which not, in this way establishing the basis for a future extrapolation to an NPP scaled calculation. The application of the UPC scaling up methodology has demonstrated that selected phenomena can be scaled-up and explained between counterpart simulations by carefully considering the differences in scale and design.

\section{Introduction}

Computational analyses of full-scale nuclear power plants (NPP) have a wide and consolidated application on nuclear engineering. Most of the uses of NPP nodalizations, related to the support to plant operation and control, have been extensively described in two different safety reports $[1,2]$ by the International Atomic Energy Agency (IAEA) $[1,2]$. The first one [1] is specifically devoted to detail the guidelines for the development of power plant nodalizations by the use of system codes. During the last 20 years, the Technical University of Catalonia (UPC) has completed several works in this field following similar strategies as in [1]. The description of some of these contributions can be found in [3-7] which deal with the development and usage of NPP nodalizations in the support to plant operation and control. This experience has shown the usefulness and possibilities of this approach. One of the major outcomes is that the continuous development and improvement of NPP nodalizations are not only a requirement but also a difficult task due to the large amount of information contained in a full NPP nodalization. In that sense, methodologies designed to qualify NPP nodalizations take a key role and can be used to both provide an insight in the quality of the produced analyses and, in addition, help the developer in the detection of possible deficiencies in the nodalization.

In a related paper [8], the UPC scaling-up methodology was presented as a tool to contribute to qualifying NPP nodalizations. The UPC scaling-up methodology is a systematic procedure for qualifying NPP nodalizations taking advantage of the experience acquired through the posttest analysis of integral test facility (ITF) experiments. It is devoted to the nodalization qualification, which implies that the methodology can only be applied to those phenomena that have been well reproduced on ITF posttest analyses; and that the scaling analyses are only performed through code simulations. 


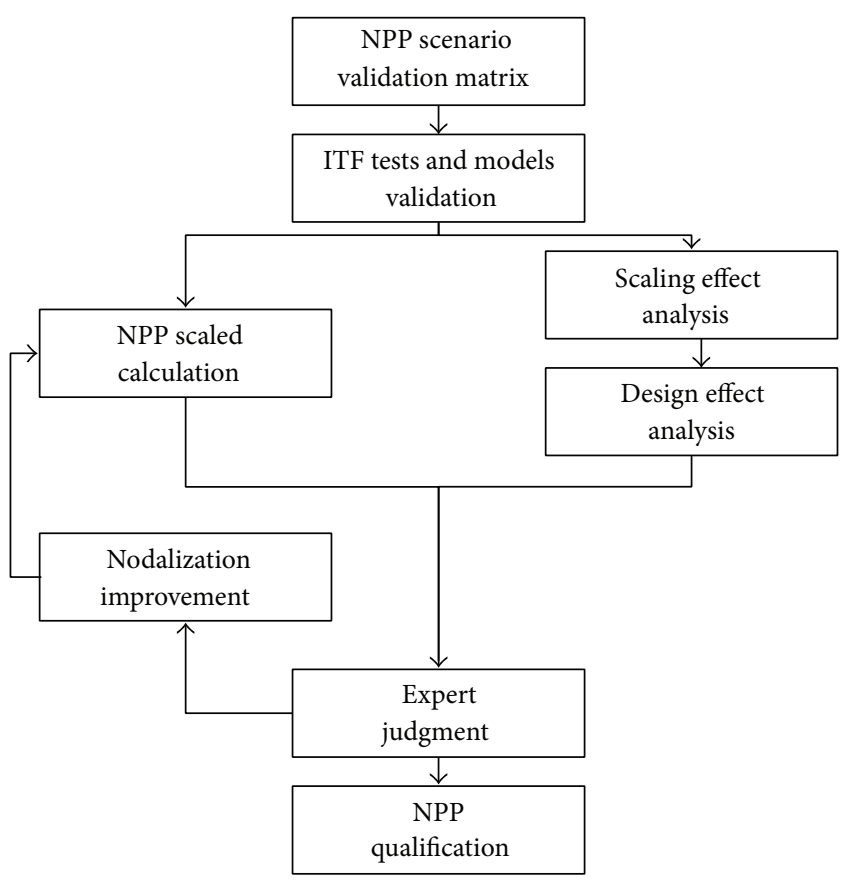

FIGURE 1: UPC scaling-up methodology.

The two main factors that affect the scaling-up of the ITF posttest simulations are the scaling-down criterion used for the design of the ITF and the differences of configuration between the ITF and the NPP. For analyzing both, the UPC scaling-up methodology applies two concepts, "scaled-up nodalizations" and "Hybrid nodalizations." The so called "scaled-up nodalizations" can be used to analyze the effect of the ITF scaling criterion in a scaled-up calculation. On the other hand, the "hybrid nodalizations" are defined as modified scaled-up ITF nodalizations in which some components have been adjusted to resemble the configuration of the NPP system. The aim of these nodalizations is to evaluate the influence of each aspect of the configuration on the ITF simulation results independently of the scale. A diagram associated with the "UPC scaling-up methodology" is shown in Figure 1, and further details on each step can be found in [8].

In the present work, the UPC scaling-up methodology is applied in order to check its capabilities for justifying and detecting the discrepancies that may appear between counterpart simulations performed with different nodalizations at different scales. For this purpose, the experiments performed within the framework of the OECD/NEA ROSA2 and PKL-2 projects are used. These two projects are related to experiments at the two correspondent ITFs: the Primärkreislauf (PKL) test facility [9] operated by AREVA and the Large-Scale Test Facility (LSTF) [10] operated by the Japan Atomic Energy Agency (JAEA). During 2011, a link was established between the two projects in order to perform a counterpart experiment with the two facilities. The objective of the counterpart test was to represent the same accident conditions with two different scaling criteria and at different local geometries in order to evaluate their effect on the evolution of the transient. In this work, the ROSA-2 Test
3 and the PKL-2 Test G7.1 (also known as counterpart tests) will be simulated, qualified, and analyzed applying design effect analyses and scale effect analyses which are part of this particular methodology (see Figure 1).

\section{Facilities and Test Description}

2.1. LSTF. LSTF is an experimental facility operated by JAEA; it is designed to simulate a Westinghouse-type 4-loop 3,420 MWth PWR under emergency conditions. It is a fullheight and 1/48 volumetrically-scaled two-loop system with a maximum core power of $10 \mathrm{MW}$ (14\% of the scaled PWR nominal core power) and pressures scaled $1: 1$. Loops are sized to conserve volumetric factor $(2 / 48)$ and to simulate the same flow regime transitions in the horizontal legs (preserving $L / \sqrt{D}$ factor).

There is one SG for each loop respecting the same scaling factors. They have 141 full-size U-tubes, inlet and outlet plena, steam separator, steam dome, steam dryer, main steam line, four downcomers, and other internals.

All emergency systems are represented and have a big versatility referred to their functions and positions. Many break locations (a total of 20) are available too.

LSTF test facility has about 1,760 measurement points that allow an exhaustive analysis of the tests. There are two types of data or measurements of interest: directly measured quantities (temperature, pressure, and differential pressure) and derived quantities (from the combination of two or more direct measured quantities: coolant density, mass flow rate etc.).

2.2. PKL. PKL is an ITF which reproduces the entire primary system and most of the secondary system (except for the turbine and condenser) of a $1300 \mathrm{MW}$ PWR plant operated by AREVA. It is based on a four-loop Siemens design (KWU), with elevations scaled 1:1 and volumes and power reduced by a factor of 145. The number of rods in the core and the Utubes in the steam generator has been divided by 145 as well following the power-to-volume scaling criterion. The core has been modeled by 314 electrical heater rods. Unlike many experimental facilities with only two available loops (one for the broken loop and one to simulate the other three intact loops) PKL simulates all four loops separately. This is very important in order to analyze asymmetrical transients, for example, with injection in two out of four loops.

The operating pressure of the PKL facility is limited to 45 bars on the primary side and to 56 bars on the secondary side. This allows simulation over a wide temperature range (522 K to $322 \mathrm{~K}$ ) that is particularly applicable to the cooldown procedures investigated, although it limits the simulation of the high-pressure phases of some events, for instance, the initial phase of an SBLOCA.

All emergency systems are represented and have a wide versatility referred to their functions and positions. The pump injection system is available in all the hot and cold legs. Many break locations are available too.

PKL test facility has about 1500 measurement points that permit an exhaustive analysis of the tests. Sixty of 
TABLE 1: PKL and LSTF major features.

\begin{tabular}{|c|c|c|}
\hline & LSTF & PKL \\
\hline Reference plant & Westinghouse & $\begin{array}{c}\text { KWU } \\
\text { (Siemens design) }\end{array}$ \\
\hline Height & Full & Full \\
\hline Volumetric scaling & $1 / 48$ & $1 / 145$ \\
\hline Number of loops & 2 & 4 \\
\hline Pressure vessel DC & Cylindrical & Double-pipe \\
\hline U-tubes/SG & 141 & 30 \\
\hline Pressure & Full & Up to $4.5 \mathrm{MPa}$ \\
\hline Core power & $14 \%(10 \mathrm{MW})$ & $10 \%(2.5 \mathrm{MW})$ \\
\hline $\begin{array}{l}\text { Number of electrical } \\
\text { rods }\end{array}$ & 1008 & 314 \\
\hline Axial profile & Chopped cosine & Flat \\
\hline Radial profile & 3-region & 3 -region \\
\hline ECCS & Full & Full \\
\hline Hot leg diameter (m) & 0.207 & 0.128 \\
\hline Special measurement & $\begin{array}{l}\text { Video probe, } \mathrm{O}_{2} \text { gas } \\
\text { sensor }\end{array}$ & Boron sensor \\
\hline $\begin{array}{l}\text { Number of } \\
\text { instruments }\end{array}$ & About 1760 & About 1070 \\
\hline
\end{tabular}

the measurement devices are identical to those that are used in a commercial plant to simulate what an operator would control in case of an accident.

Major features of both power-to-volume scaled-down facilities are detailed in Table 1 .

2.3. PKL-2 and LSTF-2 Counterpart Test. In 2011, a counterpart test was performed in LSTF and PKL test facilities as a part of the OECD/NEA ROSA-2 and PKL-2 projects (test 3 and test G7.1, resp.). The objective of both tests was devoted to analyze two aspects:

(i) core exit temperature (CET) measurement effectiveness in accident management (AM) of NPPs;

(ii) scaling effects between PKL and LSTF test facilities.

The selected scenario was an upward oriented $1.5 \%$ hot leg SBLOCA. System failures as no high-pressure safety injection and no automatic secondary-side safety cooldown were imposed. The particular test conditions are described in the sections below.

2.3.1. ROSA-2 Test 3 Test Conditions. This test was divided into three phases, a high-pressure phase, reproducing the NPP scenario at full pressure; a low-pressure phase, reproducing the same scenario at counterpart conditions with PKL; and finally, an intermediate phase, with the purpose of conditioning the LSTF conditions at the end of the highpressure phase to the PKL counterpart test conditions. Table 2 shows the list of imposed conditions for each phase.

Several parameters were adjusted from the PKL test conditions with the aim of having analogous behaviors during the low-pressure phase of the transient. A scaling factor $K_{v}=2.55$ was applied for calculating the opening area of the SG's relief valves, the water volumes of the accumulators, and the injection rates of the low-pressure injection (LPI) system. Pressures in the primary and secondary systems were adjusted $1: 1$ to the PKL test conditions during the conditioning phase, and the mass inventory was reinstated in order to have a similar hot leg liquid level as expected to occur in the PKL test. Reflux and condenser conditions were established in both facilities at the beginning of the counterpart phase. Accumulators' set point was reduced to 2.6 $\mathrm{MPa}$ for including their actuation in both facilities.

2.3.2. PKL-2 G7.1 Test Conditions. The PKL initial conditions were adjusted at its maximum pressures in order to reproduce as realistic as it can PWR SBLOCA reflux and condensation, core dryout, and accident management phases. The test conditions were set identical as those of LSTF low-pressure phase conditions (see Table 2).

In relation to scaling, the mass inventory in the secondary side was adjusted using $K_{v}$ factor in order to have the same ratio between liquid and energy storage in the SG's. The Core power was slightly increased above the $K_{v}$ factor to compensate the differences present between both facilities in the external heat losses.

2.3.3. Experimental Results. The results of the counterpart phases showed a close agreement for reproducing the main phenomena expected for the transient. Both facilities reproduced similarly the three parts of the transient (reflux and condensation, vapor superheating, and accident management; see Figures 2 and 3) obtaining a wide spectrum of experimental data for analyzing the relationship between CET and PCT and the effectiveness of the CET signal for AM actuations.

Some differences were detected between the results of both facilities.

(i) Core dryout: there is a delay of $280 \mathrm{~s}$ in the core dryout (see Figure 4) which modifies the timing of next phases of the transients.

(ii) CET versus PCT curve: the relationship between the CET and the PCT measurements shows different slope when the CET starts to increase (see Figure 5). Because of that, there is a discrepancy of $55 \mathrm{~K}$ in the PCT of both facilities when the condition of the AM action is achieved $\left(T_{\mathrm{CET}}>623 \mathrm{~K}\right)$.

(iii) Effectiveness of the SG depressurization takes place at a different rate in each facility. Figure 6 compares PCTs of both tests for the interval in which SG depressurization and accumulators' injection take place. Results show that for PKL facility rewetting cannot be assured without the entrance of the passive ECCS system. 
TABle 2: Test 3 test conditions.

\begin{tabular}{|c|c|c|c|c|}
\hline Event & Condition & $\begin{array}{l}\text { High-pressure } \\
\text { phase }\end{array}$ & $\begin{array}{l}\text { Conditioning } \\
\text { phase }\end{array}$ & $\begin{array}{c}\text { Low-pressure } \\
\text { phase }\end{array}$ \\
\hline Break valve opened & $t=0 \mathrm{~s}$ & * & & \\
\hline Low-pressure scram signal & $P_{\text {prim }}<12.96 \mathrm{MPa}$ & * & & \\
\hline Secondary system isolation & Scram signal & * & & \\
\hline $\begin{array}{l}\text { Initiation of primary coolant pump } \\
\text { coastdown }\end{array}$ & Scram signal & $*$ & & \\
\hline $\begin{array}{l}\text { Initiation of core power decay curve } \\
\text { simulation }\end{array}$ & Scram signal & * & & \\
\hline $\begin{array}{l}\text { Initiation of HPI coolant injection into } \\
\text { pressure vessel upper plenum }\end{array}$ & $T_{\mathrm{PCT}}>750 \mathrm{~K}$ & * & & \\
\hline Break valve closed & $P_{\text {prim }}<5 \mathrm{MPa}$ & * & * & \\
\hline Power constant & $P_{\text {prim }}<5 \mathrm{MPa}$ & & * & \\
\hline $\begin{array}{l}\text { Termination of HPI coolant injection into } \\
\text { pressure vessel upper plenum }\end{array}$ & $H_{\mathrm{HL}} \cong \frac{1}{2} \cdot H$ & & $*$ & \\
\hline SG's relief valve depressurization & $H_{\mathrm{HL}} \cong \frac{1}{2} \cdot H_{\mathrm{HL}}$ & & * & \\
\hline Secondary system isolation & $P_{\text {prim }}<3.9 \mathrm{MPa}$ & & $*$ & \\
\hline Break valve reopened & $P_{\text {prim }}>4.5 \mathrm{MPa}$ & & * & * \\
\hline SG depressurization as AM action & $T_{\mathrm{CET}}>623 \mathrm{~K}$ & & & * \\
\hline Initiation of AFW in both loops & AM action signal & & & * \\
\hline Initiation of ACC system in both loops & $P_{\text {prim }}<2.6 \mathrm{MPa}$ & & & * \\
\hline Termination of ACC system in both loops & $P_{\text {prim }}<1.2 \mathrm{MPa}$ & & & * \\
\hline Initiation of LPI system in both loops & $P_{\text {prim }}<1 \mathrm{MPa}$ & & & * \\
\hline
\end{tabular}

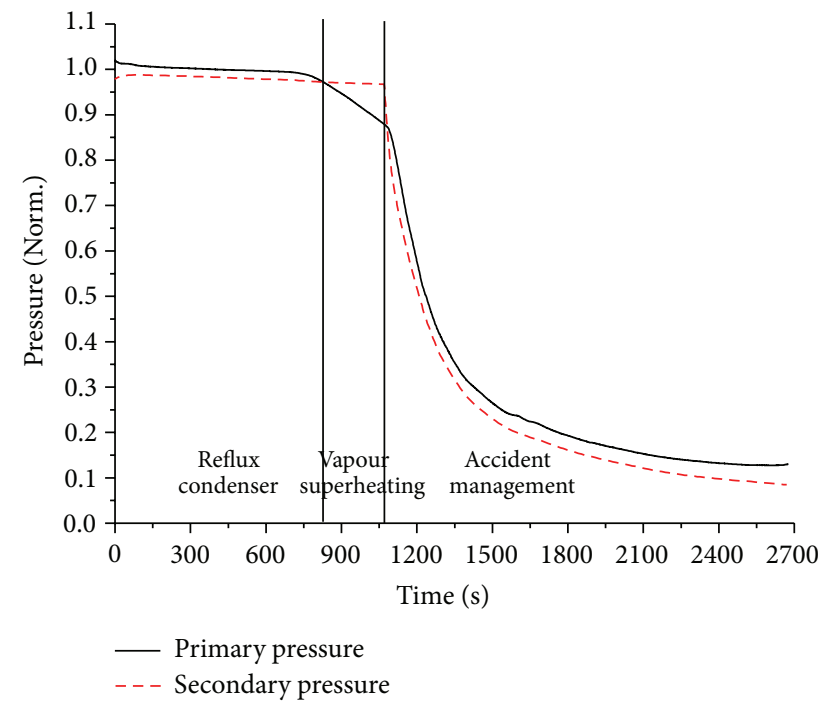

FIGURE 2: LSTF system pressures.

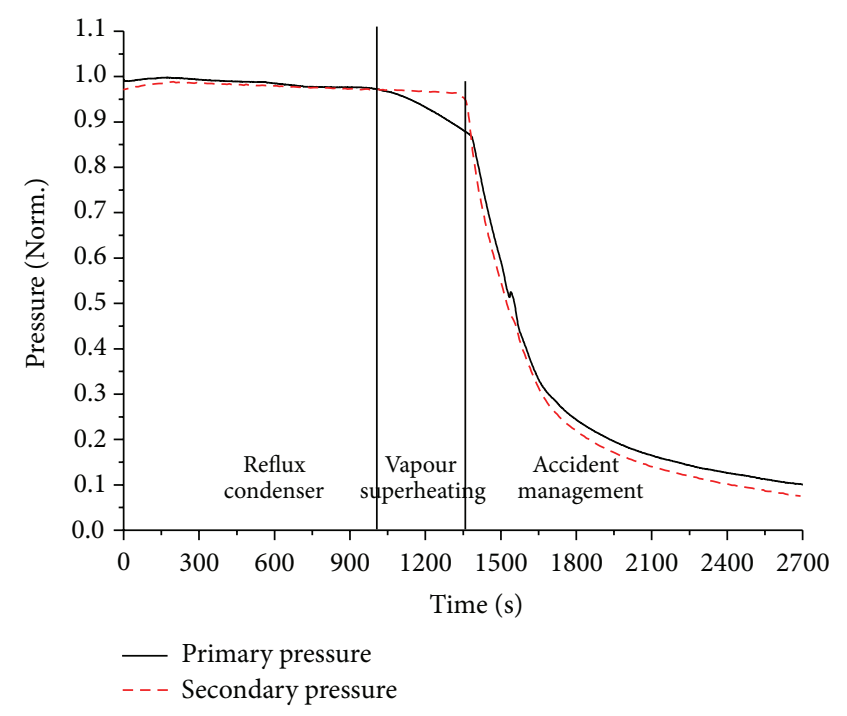

FIGURE 3: PKL system pressures.

\section{Results}

3.1. PKL G7.1 Posttest Analysis. Two calculations were performed by making use of the qualified (see [11-14]) UPC PKL RELAP5mod3.3 nodalization:
(i) UPC PKL 1D nodalization;
(ii) UPC PKL pseudo-3D nodalization.

The differences between both nodalizations were exclusively related to the core and upper plenum modeling. UPC PKL 1D nodalization simulated them with one channel (in addition to the core bypass), having fuel and all passive heat structures (core barrel and unheated rods) linked to the same volumes. The fuel was modeled with three HSs, with the same power ratio, and divided into 7 axial levels. 


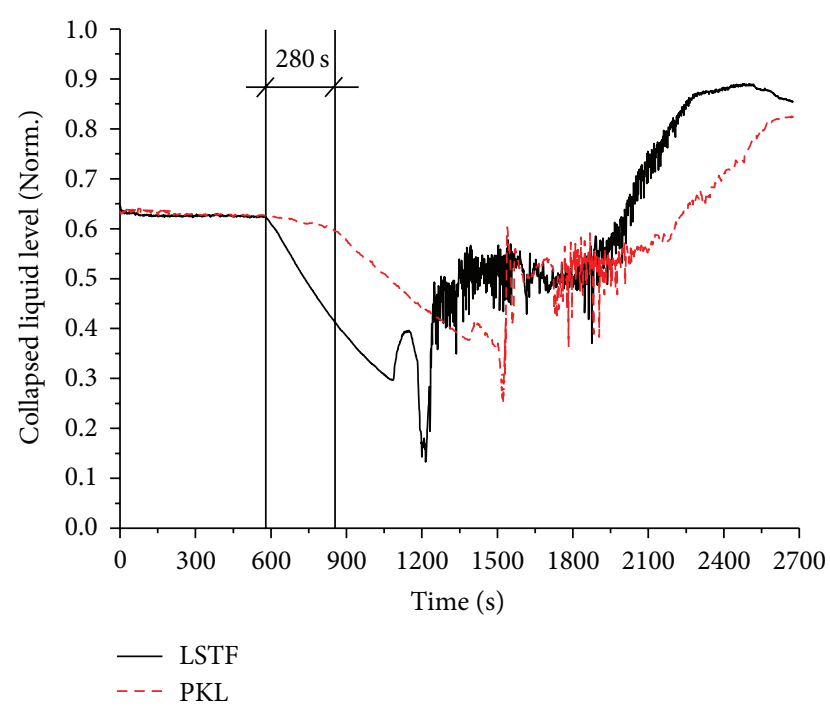

Figure 4: Core level.

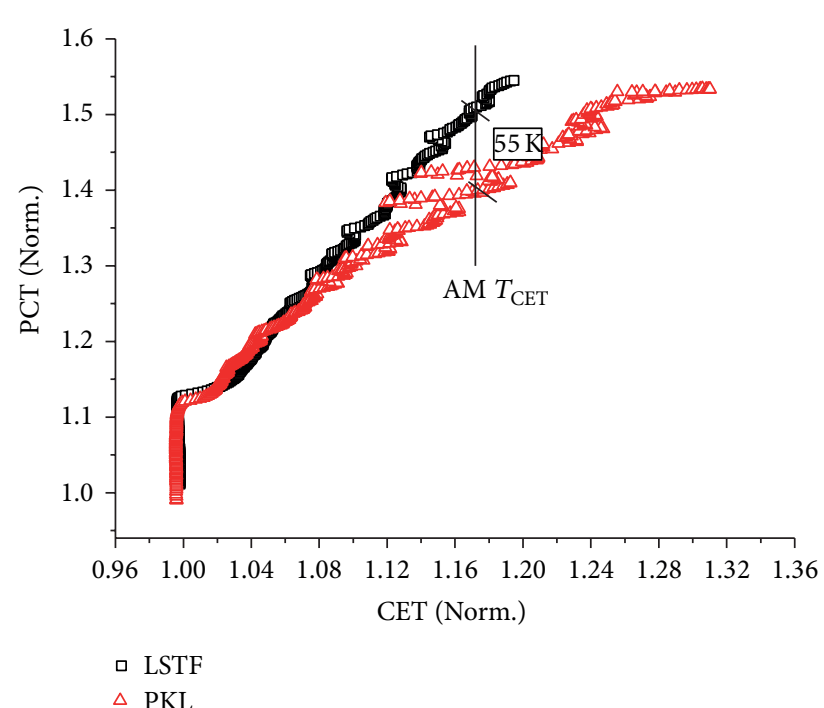

FIgUre 5: CET versus PCT curve.

UPC PKL pseudo-3D nodalization had the core and upper plenum (until the CET thermocouple level) divided into three radial channels (see Figure 7), with one fuel HS for each channel. The HSs for the passive internal metal structures were split for each channel proportionally to the flow path of each one, and the core barrel was linked to the outer zone. The radial flow paths between cells were modeled and transversal momentum equations were activated following the recommendations of reference [15]. The total number of core axial meshes was increased to 14 and the upper plenum cell heights were adjusted so that the center of the node coincided with the elevation of the thermocouples in the test facility.

The obtained results showed a quite close agreement for both nodalizations reproducing the initial conditions (see

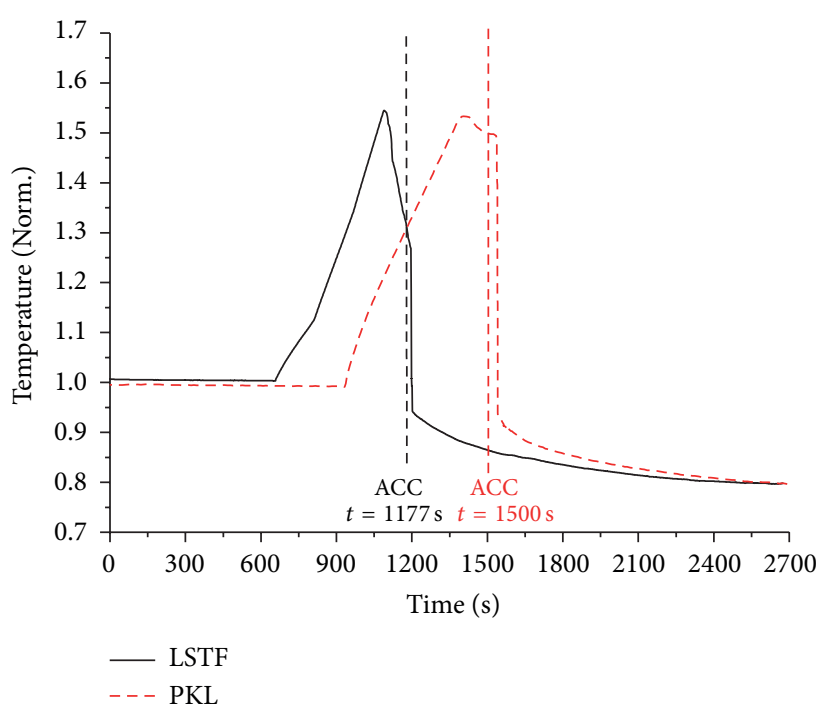

FIgURE 6: Peak cladding temperature.

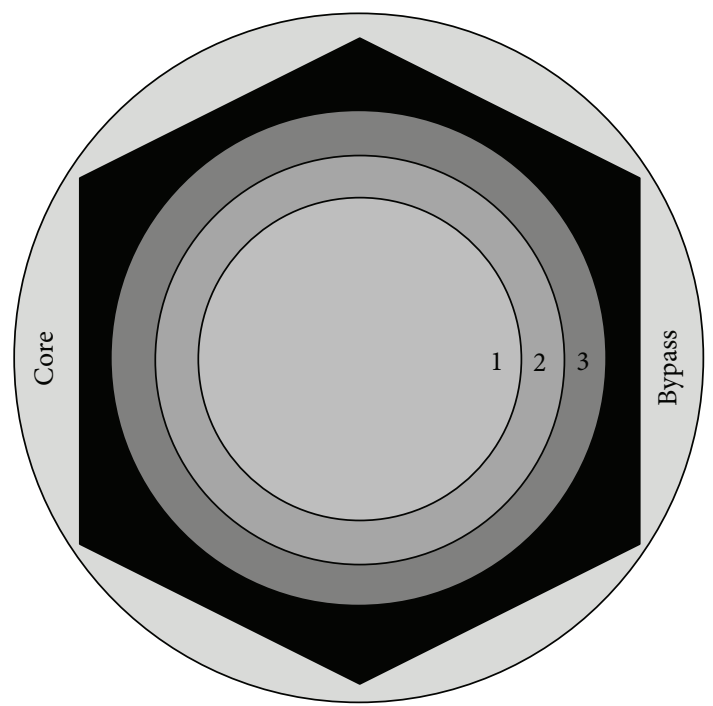

FIGURE 7: UPC PKL pseudo-3D nodalization core channels.

Table 3) as well as the general behavior of the transient (Figures 8 and 9 show a close agreement of both nodalizations for reproducing depressurization rate during three reported phases of the transient: reflux and condensation, vapor superheating, and SG depressurization). The pseudo3D nodalization provided closer results for the main events because it reduced the delay in the core uncovery (see Table 4). This was seen to be a consequence because of a higher vapor generation in the $1 \mathrm{D}$ nodalization during the phases of reflux and condensation and vapor superheating. It implied that, for similar break mass losses, liquid mass inventory decreased faster and core uncovery started before. In Figure 10, the differences between vapor generation and break mass flows are compared (the differences are calculated by subtracting the values of the pseudo-3D nodalization to the $1 \mathrm{D}$ nodalization). 
TABLE 3: Initial conditions of PKL G7.1 Test.

\begin{tabular}{lccc}
\hline & Experimental data & UPC 1D nodalization & UPC pseudo-3D nodalization \\
\hline Core power (Norm.) & 1 & 0.996 & 0.996 \\
Pressurizer pressure (Norm.) & 1 & 1 & 1 \\
Pressurizer liquid level (Norm.) & 1 & 0.7 & 0.7 \\
Secondary-side pressure (Norm.) & 1 & 1 & 0.998 \\
Secondary-side liquid level (Norm.) & 1 & 0.998 & 1 \\
Main feedwater temperature (Norm.) & 1 & 1 & 1 \\
Accumulators pressure (Norm.) & 1 & 1 & 1 \\
Accumulators temperature (Norm.) & 1 & 1 & 1 \\
LPI pressure (initiation of system) (Norm.) & 1 & 1 & 1 \\
LPI temperature (Norm.) & 1 & 1 & 1 \\
\hline
\end{tabular}

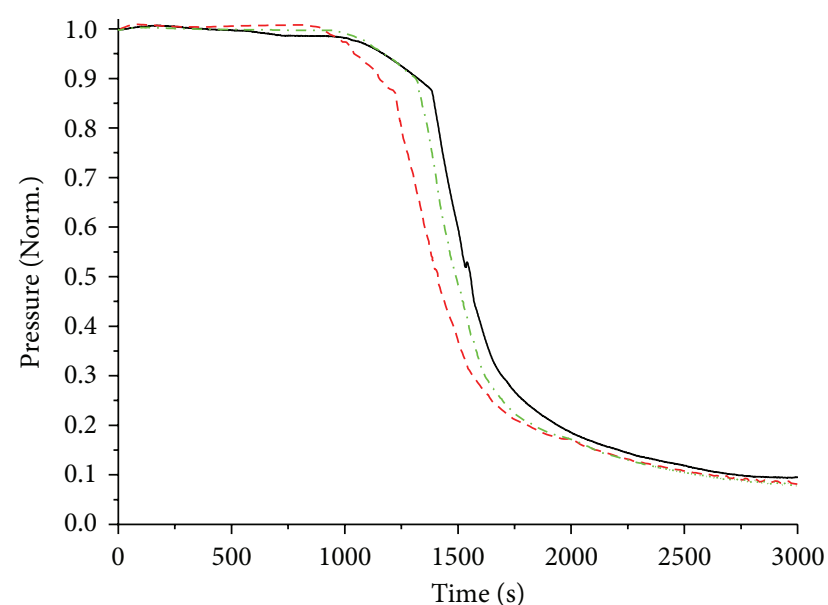

- Experimental

- - UPC 1D

-... UPC Pseudo 3D

FIgURE 8: Primary pressure.

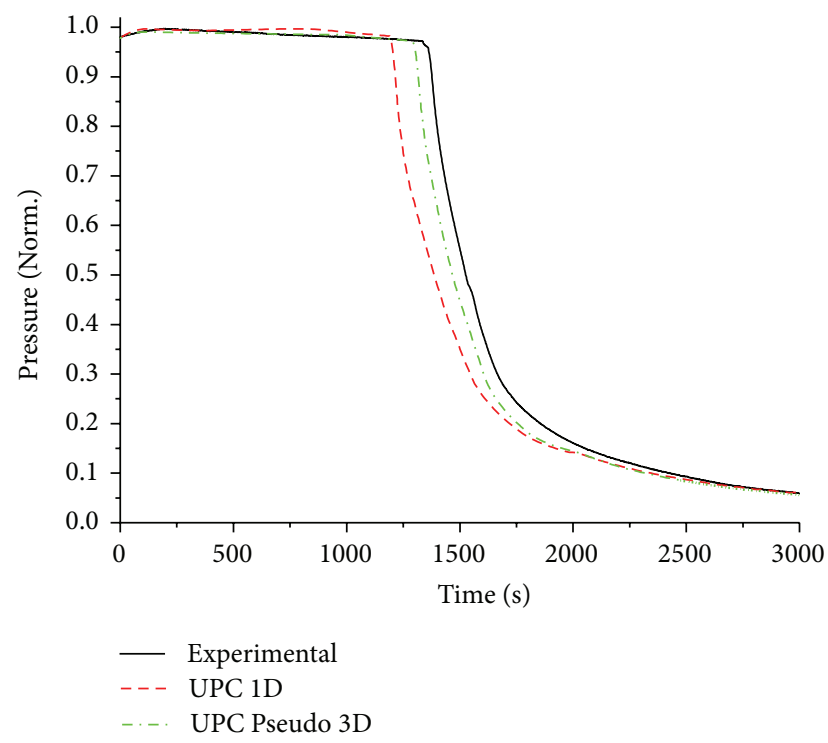

FIGURE 9: Secondary pressure.

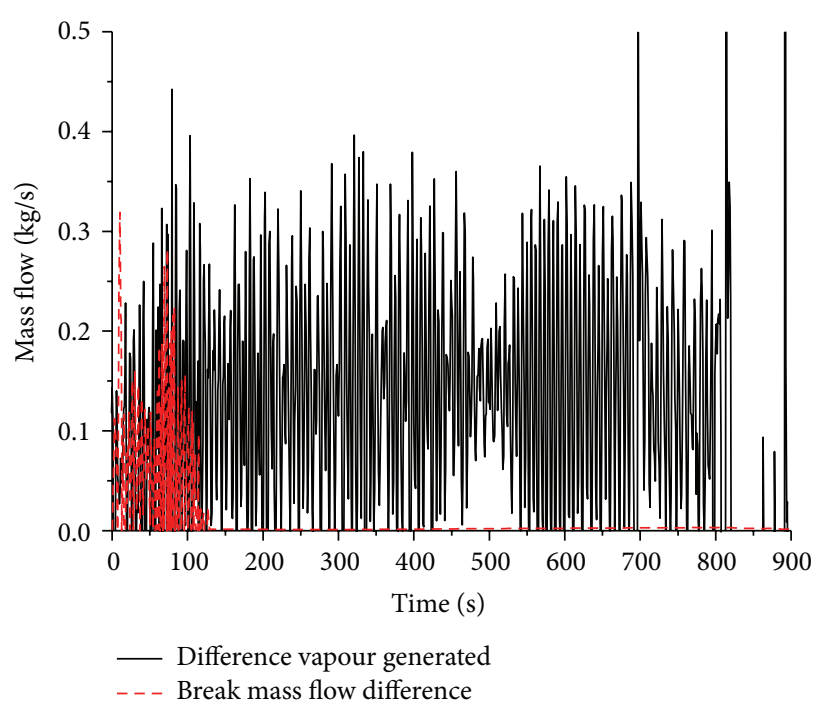

Figure 10: Mass flow comparison.

Finally, the UPC PKL pseudo-3D nodalization was qualified for reproducing the relationship between the CET and the PCT. This nodalization solved instabilities in the simulation of the overheated CET (Figure 11), obtaining close results in the CET versus PCT curve (Figure 12). The pseudo-3D nodalization reproduced the same slope of the experimental data as well as the initial increase of the PCT.

On the other hand, the pseudo-3D nodalization was not qualified for reproducing closely the core quenching after SG depressurization action. Despite, the fact that core refilling was simulated, in the calculation quench front achieved the top level of the active core before accumulators' injection, showing a discrepancy in experimental results. In Figure 11, each CET curve is associated with a vertical line that indicates the time at which the accumulators' injection starts. The comparison shows that for both simulations, the temperatures dropped before accumulators' injection, unlike experimental data, in which it did not occur.

3.2. LSTF Test 3 Posttest Analysis. A base case calculation was performed using the UPC LSTF RELAP5mod3.3 nodalization that had been qualified previously for the ROSA Test 
TABLE 4: Main events of PKL G7.1 Test.

\begin{tabular}{lccc}
\hline & Experimental (s) & UPC 1D nodalization (s) & UPC pseudo-3D nodalization (s) \\
\hline Start of the transient & 0 & 0 & 0 \\
Beginning of core uncovery & 940 & 800 & 940 \\
Primary pressure below secondary pressure & 1020 & 920 & 1010 \\
Secondary-side depressurization & 1360 & 1190 & 1295 \\
Start of accum. injection & 1500 & 1304 & 1450 \\
ACC injection finished & 1860 & 1712 & 1752 \\
LPSI started & 2060 & 1966 & 1993 \\
End of the test & 5685 & 5685 & 5685 \\
\hline
\end{tabular}

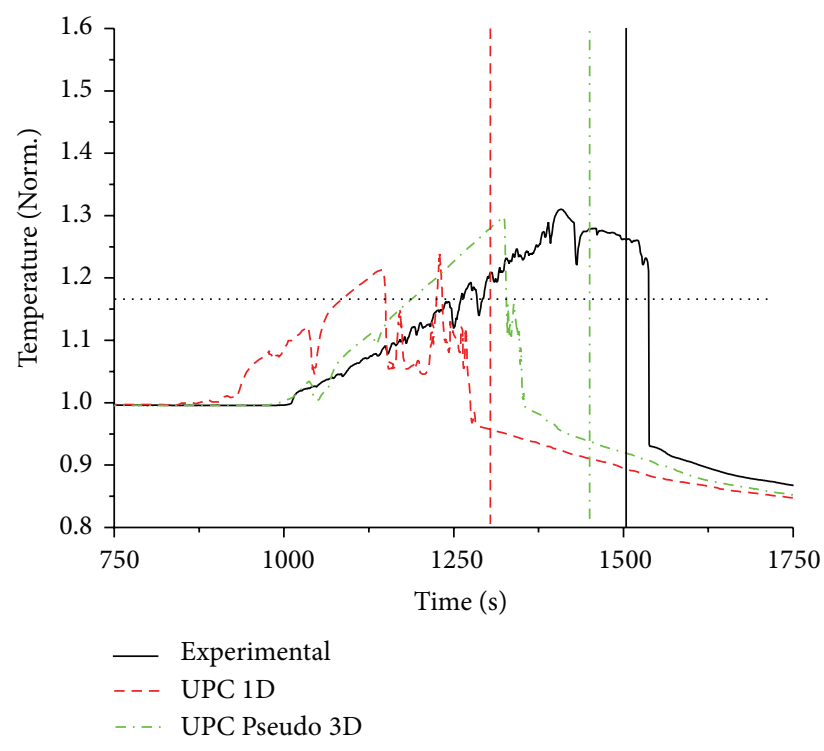

Figure 11: Core exit temperature.

3.1 and ROSA Test 3.2 transients $[16,17]$. The major features of the vessel nodalization were core and fuel modeled with one channel and one heat structure, respectively; fuel axial core power calculated as an average of the low, medium, and high experimental core power profiles; 9 fuel mesh points; characterization of passive heat structures simulating control rods, core barrel, upper core support plate, instrumentation, and external heat losses.

Results showed a quite good agreement for reproducing initial steady state conditions and main events of three phases of the transient (see Tables 5 and 6). There was a slight overestimation of the break mass losses when stratification appeared in the hot leg, so the break was in two-phase discharging mode (see Figure 13 from 750 s to 1500 s). As a result of this, core uncovery occurred slightly earlier for both phases of the transient (see Table 6), and consequently, the SG depressurization signal related with the CET was activated in advance as well (see Table 6 and Figure 14). In any case, the main parameters were consistently reproduced (see Figures 14,15 , and 16).

Focusing on the relation between the CET and the PCT, results showed a disagreement in the slope of the plots (see Figures 17 and 18). These results suggested that UPC

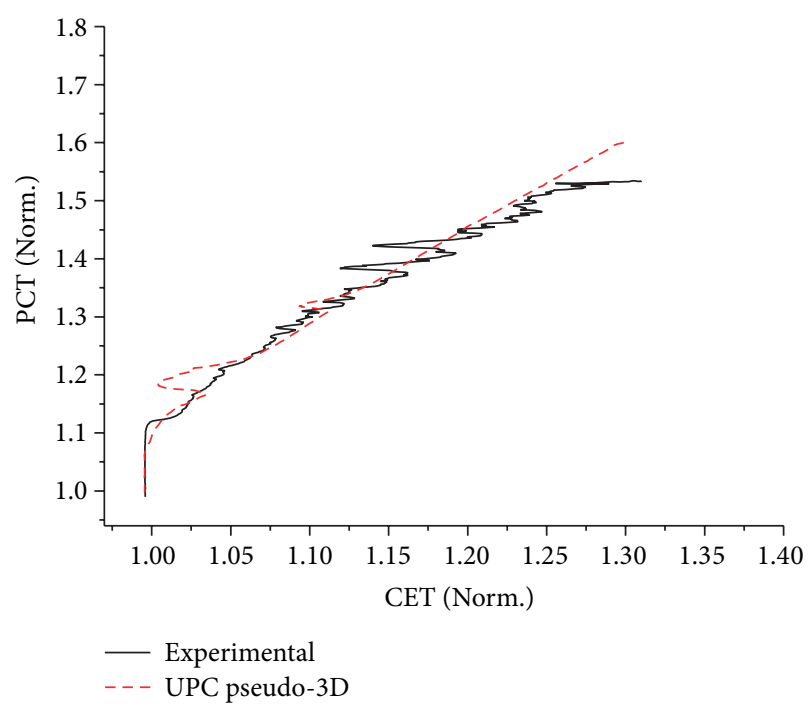

FIgURE 12: PCT versus CET correlation.

LSTF nodalization should be improved following a similar approach as the one (pseudo-3D modeling) applied in the PKL analysis.

In that sense, a UPC LSTF pseudo-3D nodalization was implemented splitting the core in 13 channels with 18 axial levels (see Figure 19). The low, medium, and high core power axial profiles were simulated, arranging them in each channel as in the experimental radial power distribution. Cartesian crossflows were used for organizing them radially and transversal momentum equations were activated in order to take into account the possible radial $\Delta P$ 's. Passive HSs were split according to the geometries. Finally, the upper plenum was modified simulating it with two channels, one hot channel, connected to the outlet of the hottest core channel, and another one simulating the rest of the plenum. Transversal momentum equations were activated too in order to consider $\Delta P$ 's in the vessel that could affect flow path to the hottest channel during the upper plenum HPI injection. On the other hand, HPI mass flow was modified in the conditioning phase in order to match primary mass inventory at the beginning of the low-pressure phase. This correction was justified for the analysis of the following counterpart phases in which the achievement of specified initial conditions is necessary. 
TABLE 5: Initial conditions of LSTF Test 3.

\begin{tabular}{lcc}
\hline & Experimental data (loops w/wo PZR) & UPC-INTE RELAP nodalization (loops w/wo PZR) \\
\hline Core power (Norm.) & 1 & 1 \\
Hot leg temperature (Norm.) & 1 & 1.001 \\
Cold leg temperature (Norm.) & 1 & 1.003 \\
Mass flow rate (×loop) (Norm.) & 1 & $1.002 / 0.998$ \\
Downcomer-to-hot-leg bypass (Norm.) & 1 & 1 \\
Pressurizer pressure (Norm.) & 1 & 1 \\
Pressurizer liquid level (Norm.) & 1 & 1.014 \\
Secondary-side pressure (Norm.) & $1 / 1$ & $1.004 / 0.997$ \\
Secondary-side liquid level (Norm.) & 1 & 0.995 \\
Main feedwater temperature (Norm.) & 1 & 1 \\
Main feedwater flow rate (Norm.) & 1 & $1.007 / 1.004$ \\
Accumulators pressure (Norm.) & 1 & 1 \\
Accumulators temperature (Norm.) & 1 & 1 \\
LPI pressure (initiation of system) (Norm.) & 1 & 1.24 \\
LPI temperature (Norm.) & 1 & 1 \\
Steam flow rate (Norm.) & 1 & $1.007 / 1$ \\
\hline
\end{tabular}

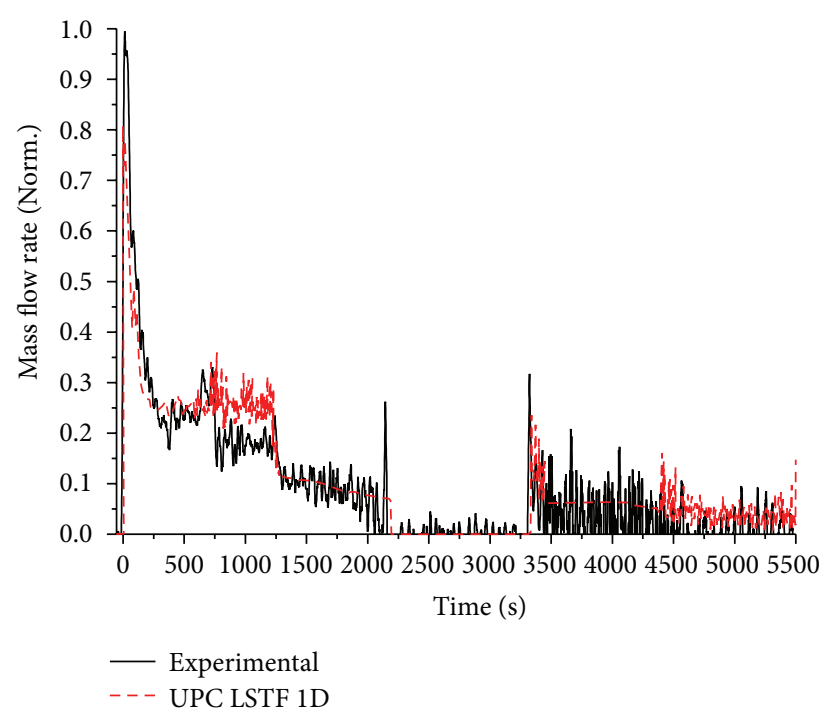

FIGURE 13: Break mass flow.

Results of the UPC LSTF pseudo-3D nodalization showed a close agreement in the simulation of the CET versus PCT relationship (see Figures 17 and 18). For both highand low-pressure transient phases, pseudo-3D nodalization reproduces the same slope and correlation with a margin of 50 and $70 \mathrm{~K}$, respectively, over AM signal established for this particular scenario $\left(T_{\mathrm{CET}}>623 \mathrm{~K}\right)$. Regarding core uncovery, the adjustment of initial mass inventory at the beginning of the counterpart phase solves the delay (see low-pressure transient phase of Table 6), obtaining a closer agreement in the simulation of reflux condenser, vapor superheating, and AM phases (see Figure 20).

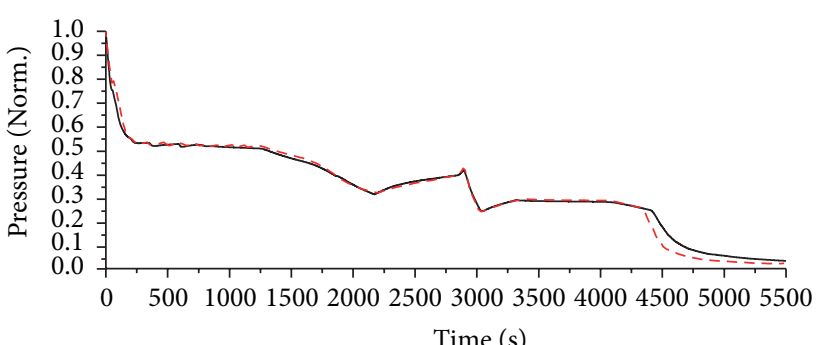

Time (s)

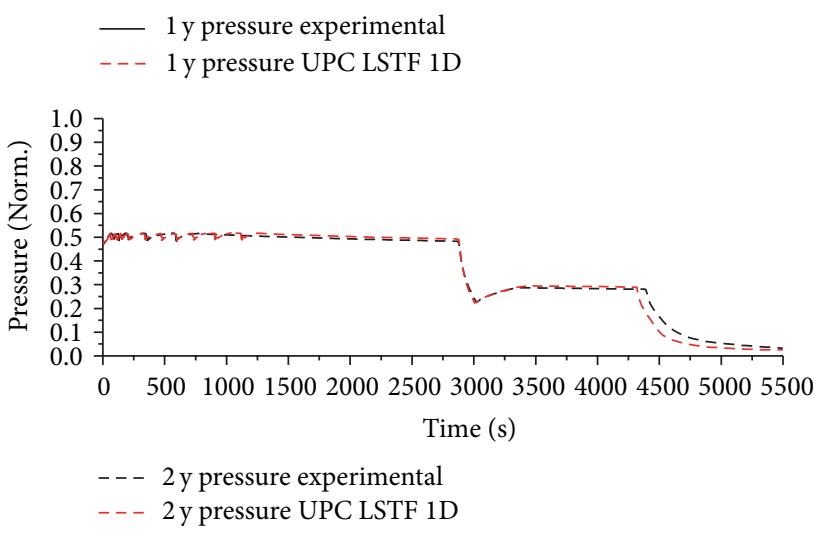

FIGURE 14: System pressures.

\section{4. "Scaling Effect Analysis" and "Design Effect Analysis" Evaluation}

Scaling and design effect analyses are two merged steps of the UPC scaled-up methodology (see Figure 1) in which the analyst can evaluate how the scale and the design modify the results of an ITF simulation. Both steps must only be applied for those phenomena that have been validated for at least two facilities with different scale and design. The effectiveness 
TABLE 6: Main events of LSTF Test 3.

\begin{tabular}{|c|c|c|c|}
\hline Event & $\begin{array}{c}\text { Experimental } \\
\text { data }(\mathrm{s})\end{array}$ & $\begin{array}{l}\text { UPC LSTF 1D } \\
\text { nodalization (s) }\end{array}$ & $\begin{array}{c}\text { UPC LSTF } \\
\text { pseudo-3D } \\
\text { nodalization (s) }\end{array}$ \\
\hline High-pressure transient phase & - & - & - \\
\hline Break & 0 & 0 & 0 \\
\hline SCRAM signal & 25 & 33 & 33 \\
\hline \multicolumn{4}{|l|}{ Turbine trip and closure MSIV } \\
\hline \multicolumn{4}{|l|}{ PZR heater off } \\
\hline \multicolumn{4}{|l|}{ Termination main feedwater } \\
\hline Initiation of coastdown of primary coolant pumps & 31 & 39 & 39 \\
\hline $\begin{array}{l}\text { Termination of continuous opening of SG relief valves, } \\
\text { termination of two-phase natural circulation, and break flow } \\
\text { from single-phase liquid to two-phase flow }\end{array}$ & 600 & 1238 & 1185 \\
\hline Core liquid level starts to decrease (core uncovered) & 1545 & 1460 & 1475 \\
\hline End high-pressure transient phase $(\mathrm{PCT}>750 \mathrm{~K})$ & 1840 & 1852 & 1778 \\
\hline Conditioning phase & - & - & - \\
\hline HPI system activated & 1850 & 1862 & 1788 \\
\hline Break valve closed & 2163 & 2169 & 2161 \\
\hline HPI system closed & 2852 & 2852 & 2852 \\
\hline SG depressurization & 2880 & 2892 & 2880 \\
\hline Termination of SG depressurization & 3024 & 3008 & 3012 \\
\hline End of Conditioning phase (break valve reopening) & 3323 & 3323 & 3323 \\
\hline Low-pressure transient phase & - & - & - \\
\hline Break valve reopening & 3323 & 3323 & 3323 \\
\hline Primary pressure lower than SG secondary pressure & 4108 & 4085 & 4105 \\
\hline SG depressurization $(\mathrm{CET}>623 \mathrm{~K})$ & 4392 & 4297 & 4388 \\
\hline Initiation of accumulator system (primary pressure $=2.6 \mathrm{Mpa}$ ) & 4505 & 4419 & 4488 \\
\hline Initiation of LPI system (primary pressure $=1.0 \mathrm{Mpa}$ ) & 5005 & 4660 & 4741 \\
\hline End of the transient & 5500 & 5500 & 5500 \\
\hline
\end{tabular}

of these techniques has been checked taking advantage of the posttest calculations described above. In that sense, PKLLSTF counterpart test becomes useful in that it relates two facilities to different scale and design (see Table 1).

Once the posttest analyses are described, the experimental differences reported in Section 2.3.3 must be checked in order to guarantee the validation of the related phenomena in the simulation. The following can be concluded.

(i) CET versus PCT correlation discrepancies: UPC LSTF and PKL nodalizations were qualified for simulating CET versus PCT correlation in that they reproduce the phenomenon with close results (see Figures 12, 17, and 18).

(ii) Core dryout delay: once initial mass inventory was readjusted in the LSTF pseudo-3D nodalization for the low-pressure transient phase, the results of both simulations showed a quite good agreement in the reproduction of the core uncovery (see Tables 4 and 6 ), reproducing qualitatively well the timing of the three phases of the transient in each case. The same criteria were applied in both nodalizations for the modelling of the core (which affects vapor generation) and the break (which affects primary mass inventory); therefore, both simulations were qualified showing a qualitative consistency with respect to experimental data in at least two different facilities.

(iii) SG depressurization effectiveness: results of the PKL simulation showed the inefficacy of UPC PKL nodalization for reproducing the effect of the SG depressurization in the CET (see Figure 11). For this case, PKL nodalization is not qualified and no further analysis can be done.

4.1. Scaling Effect Analysis. The aim of the scaling effect analysis step is to generate an idealized ITF scaled-up nodalization in which the effects of the scaling are minimized. ITF posttest calculation must be scaled to the size of the analyzed facility/NPP nodalization following the scaling criteria applied in the design of the experimental facility. The reported distortions of the scaling criteria must be studied in order to evaluate how they modify the results and in order to generate an idealized input deck without their effects. Only in the case where the scaling effects have been removed, the design effects can be analyzed. 


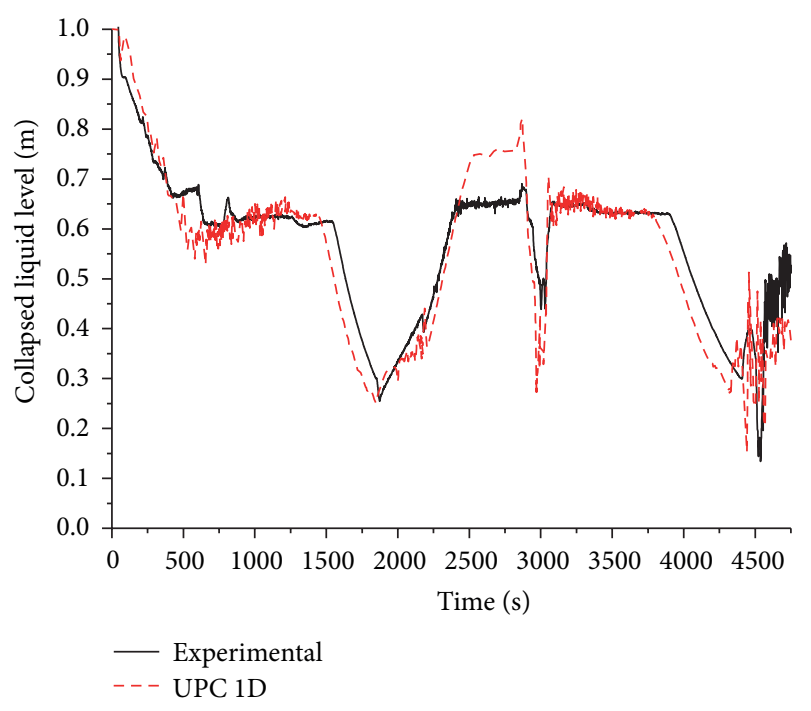

Figure 15: Core level.

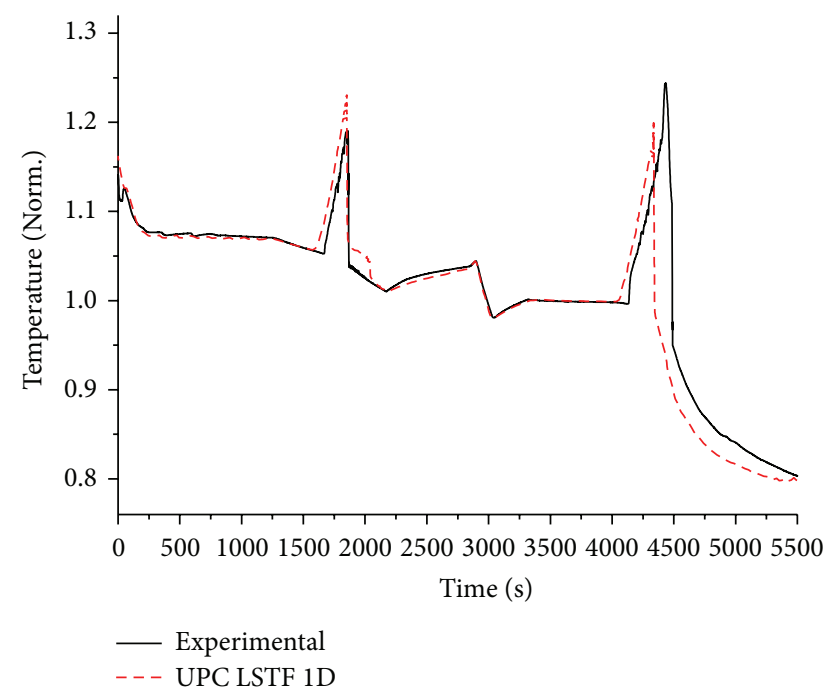

FIgURE 16: Core exit temperature.

In the case of the PKL and the LSTF experimental facilities, the power-to-volume scaling method was followed for their design. For this criterion, scaling distortions are mainly related to changes in hydraulic diameter, which affects the external heat losses, energy storage in passive structures, friction effects, and flow regime transitions (for more detailed information see the related paper [8]). For analyzing scaling effects of the counterpart test, PVST software (general description in paper [8]) has been applied to the validated UPC PKL pseudo-3D nodalization.

As a first step, a nodalization (named Sc-up nodalization A) has been generated using the PKL-LSTF $K_{v}$ factor suggested by the PKL and LSTF operator agents. This nodalization follows the power-to-volume (PtoV) scaling criterion, so that a PKL nodalization has been obtained with the same size in power and in volume as of those of LSTF. The comparison

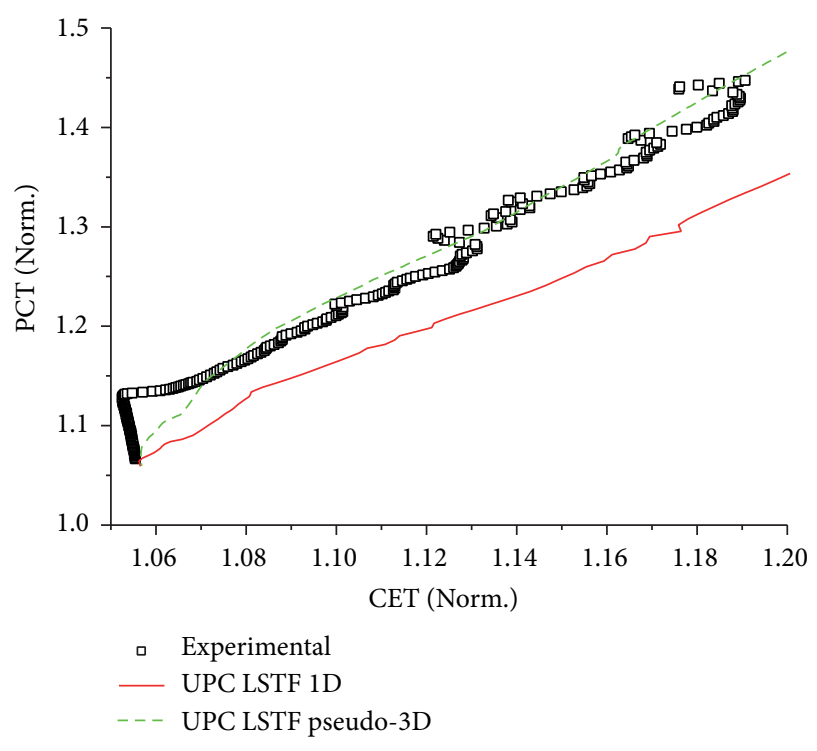

FIGURE 17: PCT versus CET curve during high-pressure transient phase.

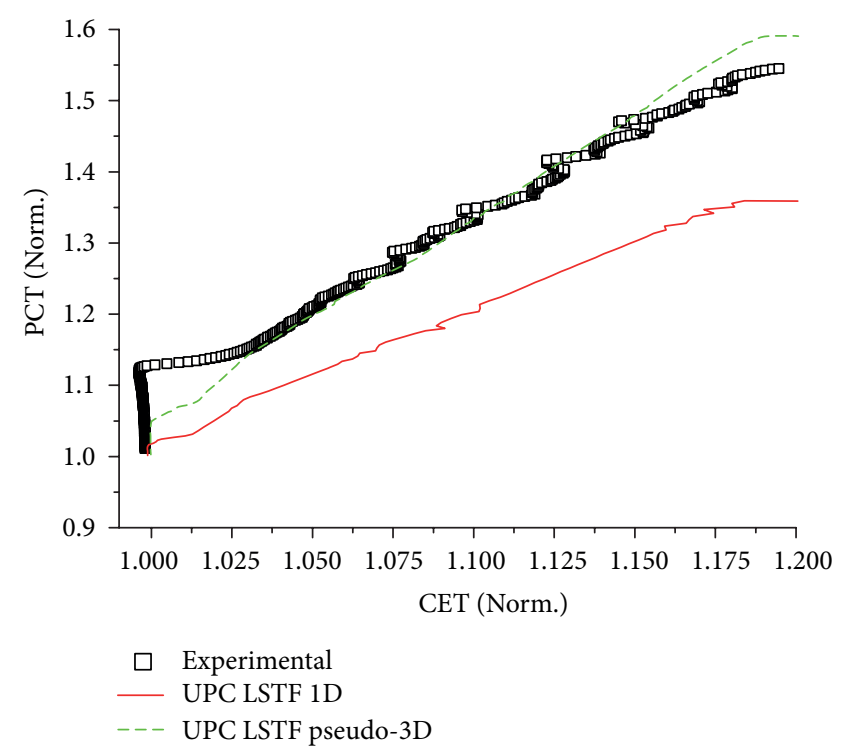

FIGURE 18: PCT versus CET during low-pressure transient phase.

between Sc-up nodalization A and the UPC PKL pseudo$3 \mathrm{D}$ nodalization shows discrepancies in the system pressures during reflux condenser and vapor superheating phases (see Figure 21) despite having similar mass discharged through the break (see Figure 22: the slight discrepancy is because primary pressures are not equal). The secondary pressure is higher for Sc-up nodalization A, pushing up the coupled primary pressure during reflux condenser phase.

In order to analyze this distortion, a new nodalization, Scup nodalization B, is generated. This is a PKL PtoV scaledup nodalization (as Sc-up nodalization A) in which the heat impact of external heat structures has been preserved. The comparison between the two posttest calculations of Sc-up 


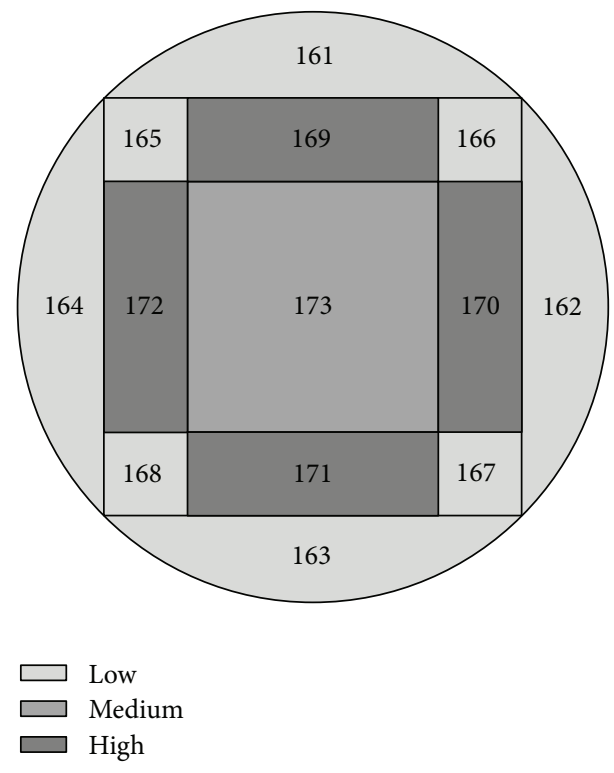

FigURE 19: UPC LSTF pseudo-3D nodalization core channels.
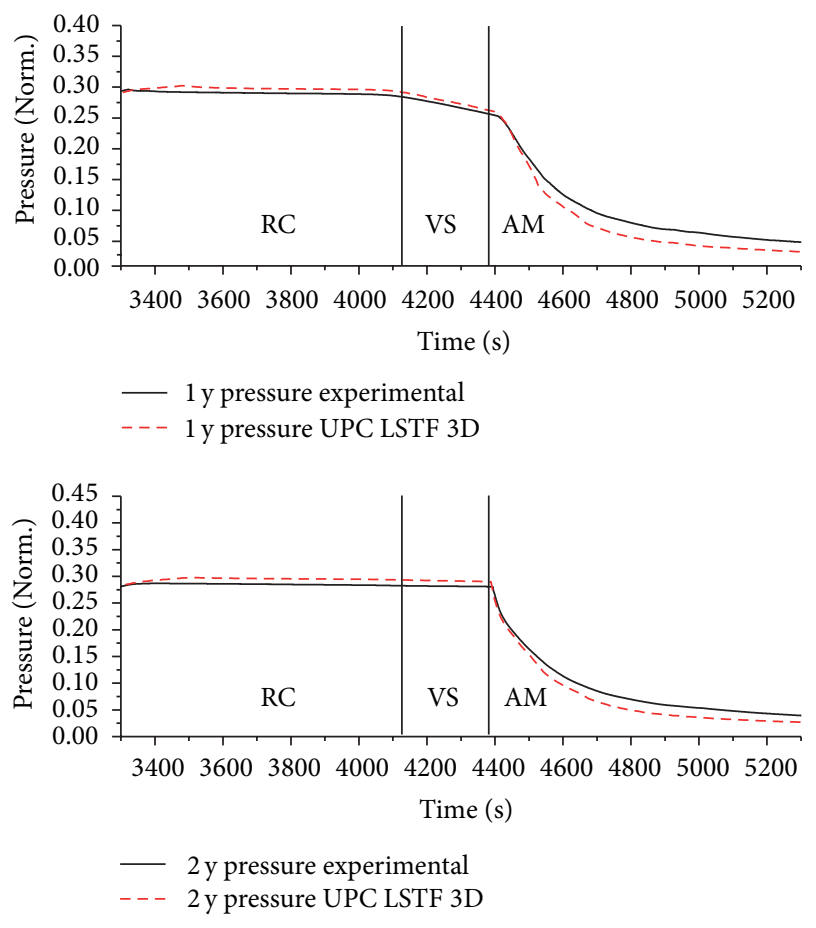

FIGURE 20: System pressures.

nodalization A and Sc-up nodalization B confirms that a distortion should be expected in the system pressures as a result of the reduction in the external heat losses (see Figure 21). Because the external heat losses are reduced when PtoV scale is increased, part of this energy is stored in the isolated secondary system, increasing pressures during reflux condenser phase.
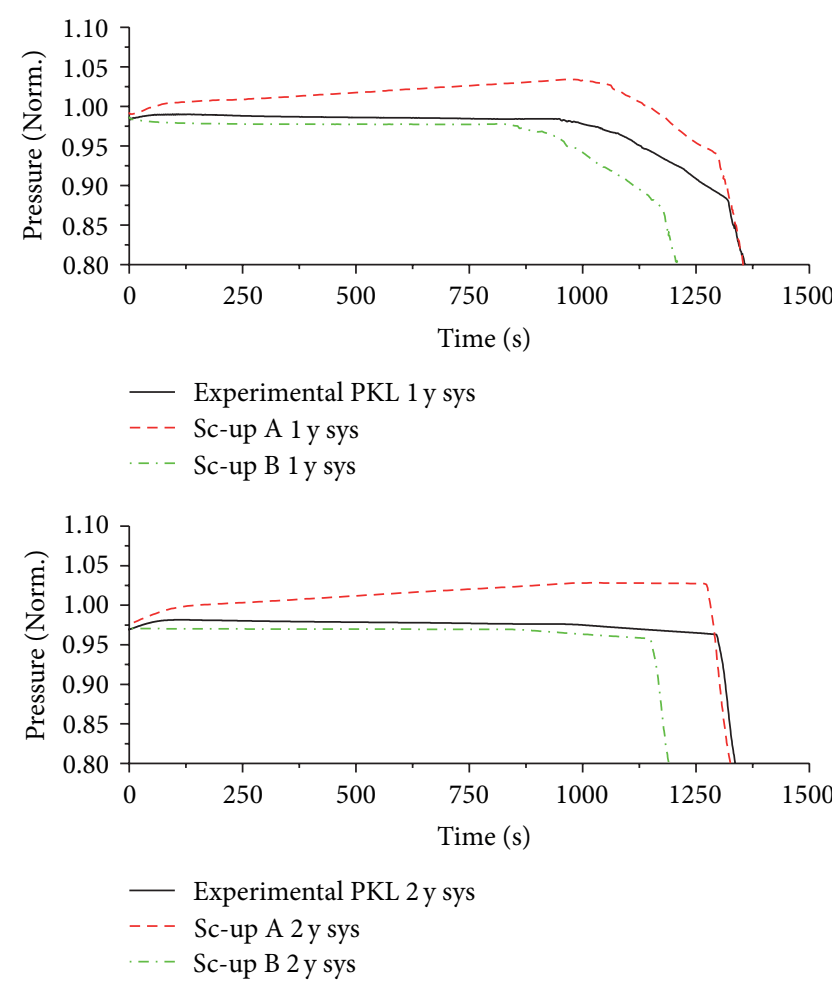

FIGURE 21: System pressures.

Once the external heat losses distortion is corrected, a discrepancy appears in the timing of the SG depressurization signal (see Figure 21). Taking into account that the aim of the scaling effect analysis is to generate an idealized PKL scaled-up nodalization in which scaling effects are minimized, another scaled-up nodalization must be generated following the previous nodalizations. Therefore, a third nodalization Sc-up nodalization C is produced based on Sc-up nodalization B but with the additional preservation of the $L / \sqrt{D}$ quotient in the hot legs. Keeping this ratio in the horizontal legs, the Froude number and the flow regime transitions should be preserved. The comparison between the PKL posttest calculation and the results obtained by Sc-up nodalizations $\mathrm{B}$ and $\mathrm{C}$ shows that the hot leg liquid levels in the broken loop are preserved for Sc-up nodalization $\mathrm{C}$ during the conditioning phase of the PKL transient (see in Figure 23 from $-4000 \mathrm{~s}$ to $-3500 \mathrm{~s}$ and from $-2750 \mathrm{~s}$ to $-2500 \mathrm{~s}$ intervals), thus providing similar break mass flow rates as in the posttest calculation (see Figure 24). This allows keeping the same primary mass inventory ratio at the beginning of the transient, obtaining similar liquid levels in the hot leg of the broken loop (see Figure 25) and similar break mass flow rates (see Figure 26). This good performance of the mass discharging removes the delay in the core uncovery obtaining a close agreement in the timing of the SG depressurization (see Figure 27).

After removing the Froude number distortion, the main parameters of the transient are compared between UPC PKL 


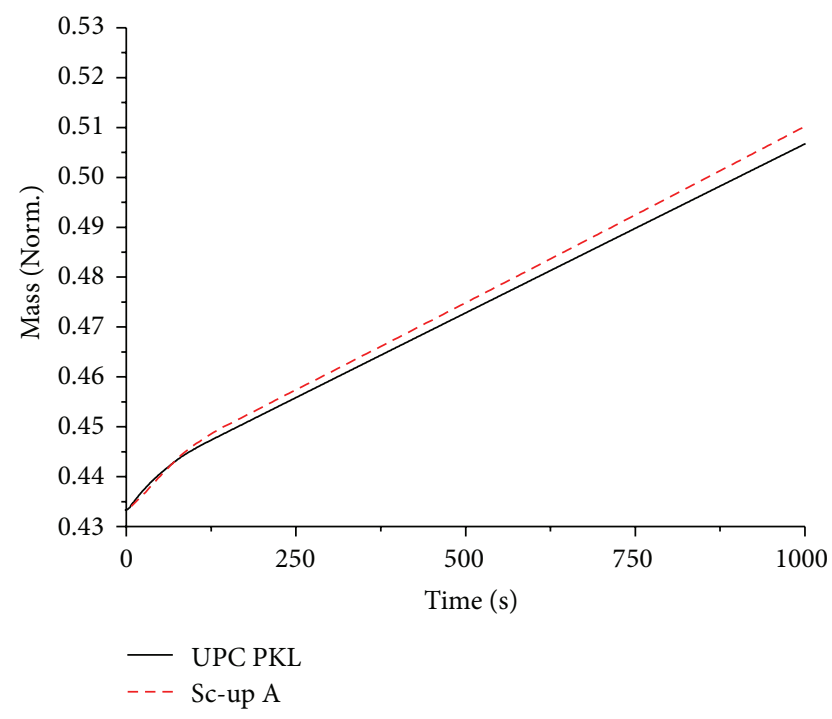

FIGURE 22: Mass discharged through the break.

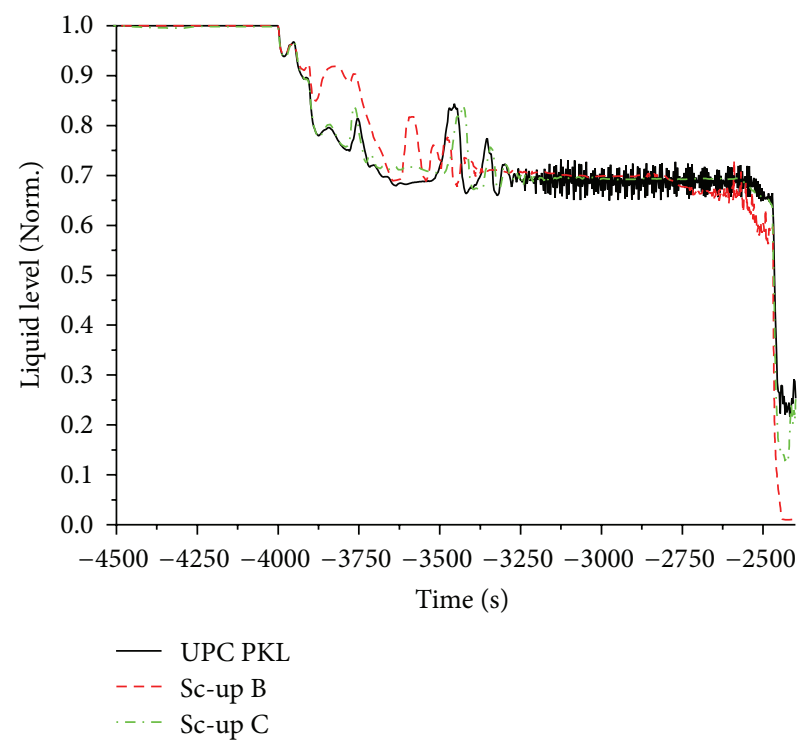

FIGURE 23: HL liquid level.

pseudo-3D nodalization calculation and the Sc-up nodalization $\mathrm{C}$ calculation in order to assure that an idealized scaledup nodalization has been obtained. Results of the system pressures (Figure 27), CET temperatures (Figure 28), and PCT temperatures (Figure 29) display a close agreement between the posttest and Sc-up nodalization C. Since the discrepancies to be analyzed between PKL and LSTF simulations are the core uncovery delay and the CET versus PCT correlation, no further scaling effect analysis will be necessary. Friction effects or hydraulic diameters in components where mixing or interface drag occurs (i.e., SG and vessel downcomers) could be studied until a perfect idealized scaled-up nodalization is obtained, but as for this transient, they will not add any relevant scaling effect in the reported LSTF-PKL discrepancies, it would suppose an unnecessary extra work

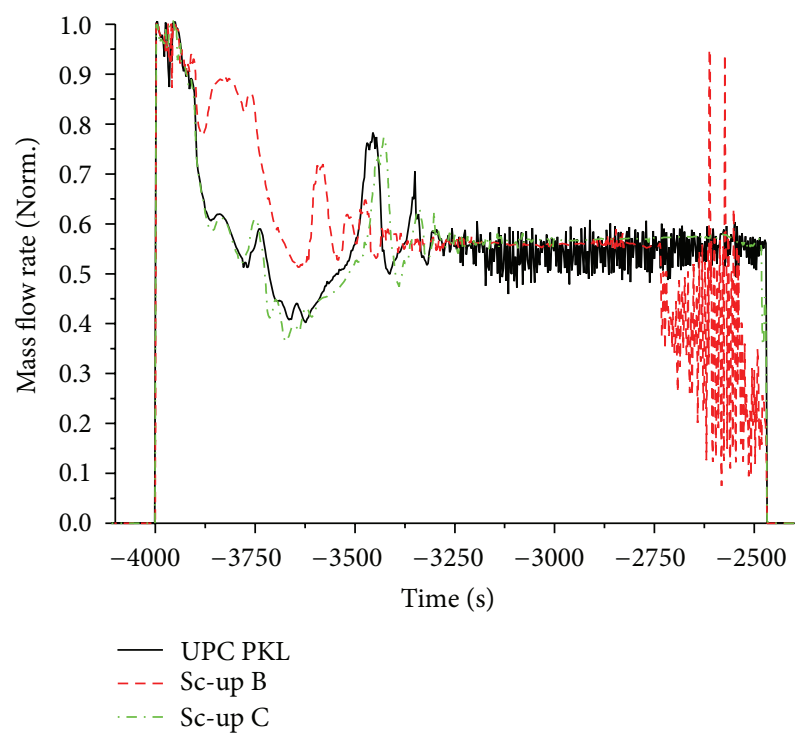

Figure 24: Break mass flow rate.

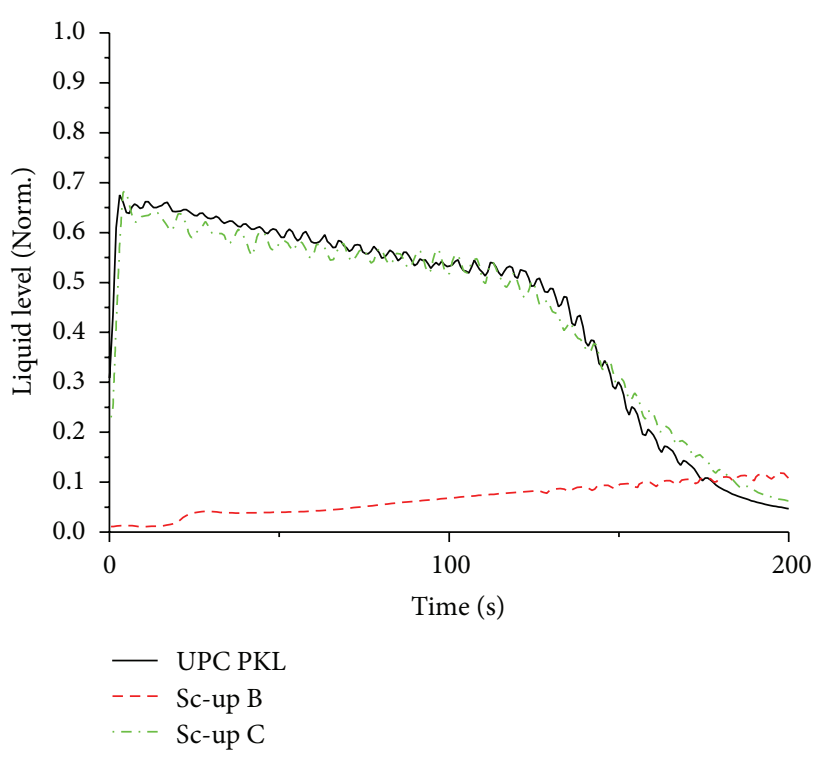

FIGURE 25: HL liquid level.

for the analyst. It is in that point where the expert judgment is essential.

4.2. Design Effect Analysis. Once an idealized PKL scaled-up nodalization has been generated, discrepancies between both counterpart simulations can be analyzed. For this purpose hybrid nodalizations will be compared with qualified LSTF posttest simulation and the idealized PKL scaled-up nodalization. Hybrid nodalizations will include LSTF components in the PKL nodalization in order to check how they modify the results.

4.2.1. Core Dryout Delay. The comparison between UPC LSTF pseudo-3D nodalization and $P K L$ idealized scaled-up 


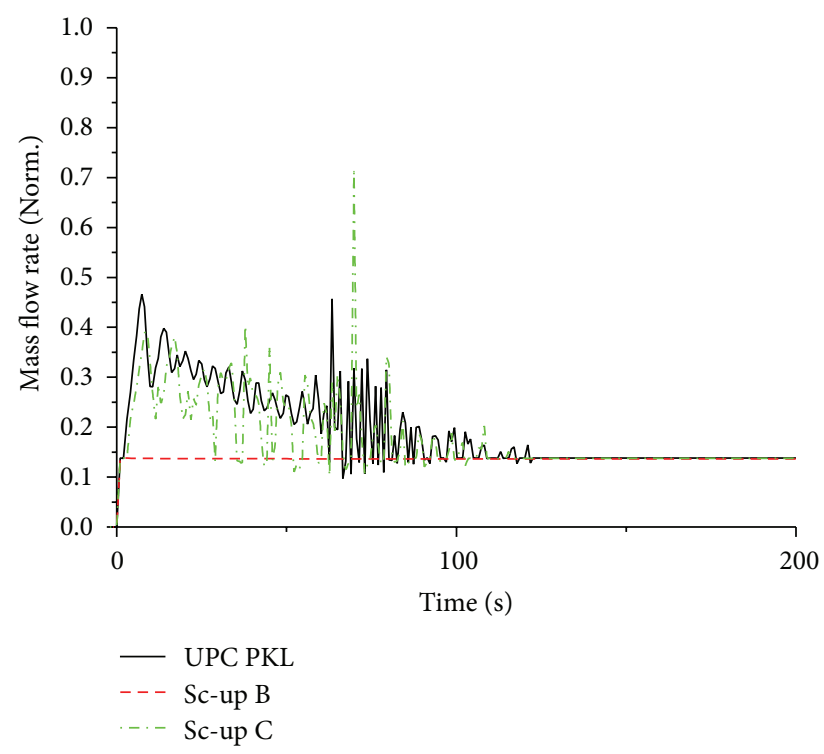

FIgURE 26: Break mass flow rate.
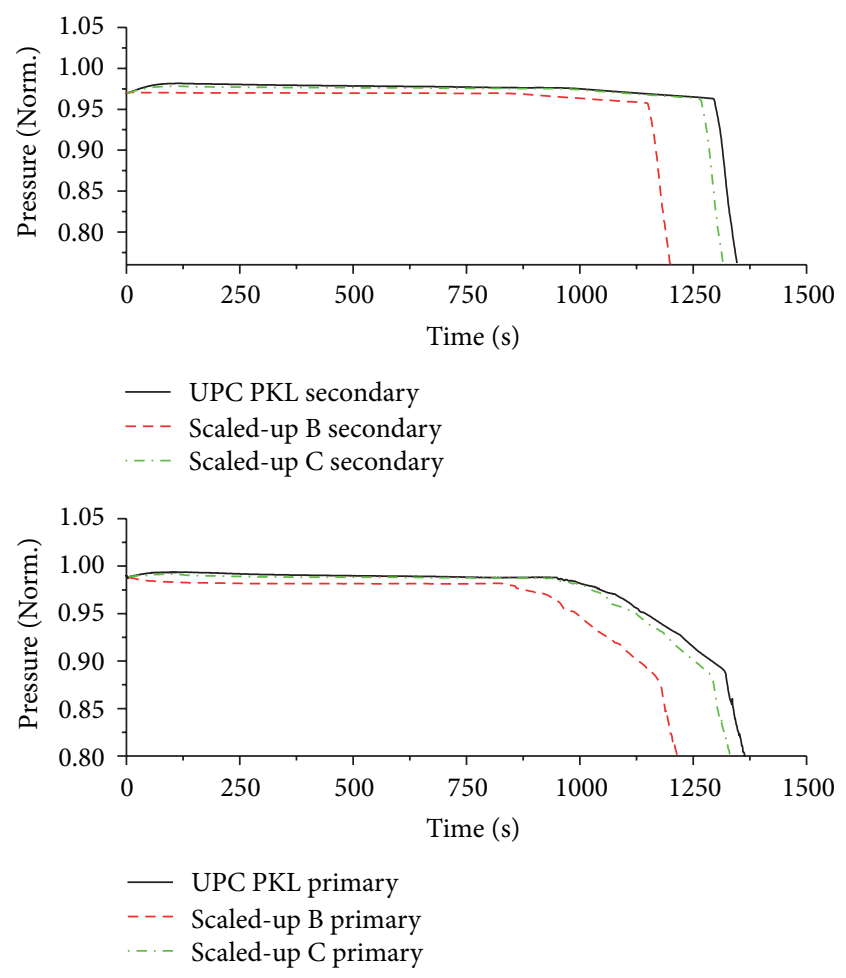

FIGURE 27: System pressures.

nodalization (Sc-up nodalization $\mathrm{C}$ of the previous step) shows a disagreement in the core dryout timing despite having a similar amount of water in the primary system (see Figures 30 and 31). For analyzing this discrepancy a $P K L$ hybrid base nodalization has been generated in order to adapt those scaling effects reported in the previous steps to the intrinsic design characteristics of the LSTF facility. In other words, the idealized PKL scaled-up nodalization is

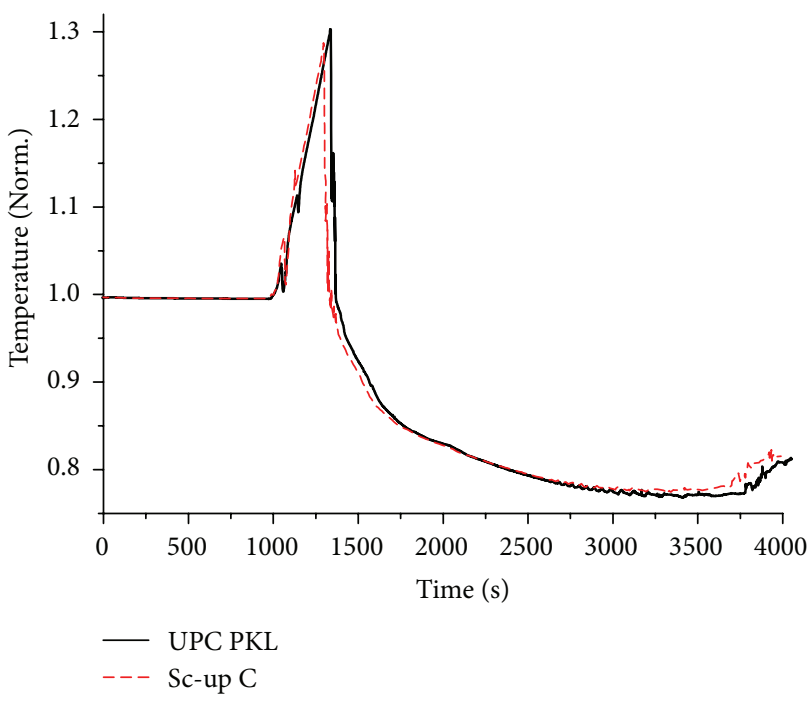

FIgURE 28: Core Exit temperature.

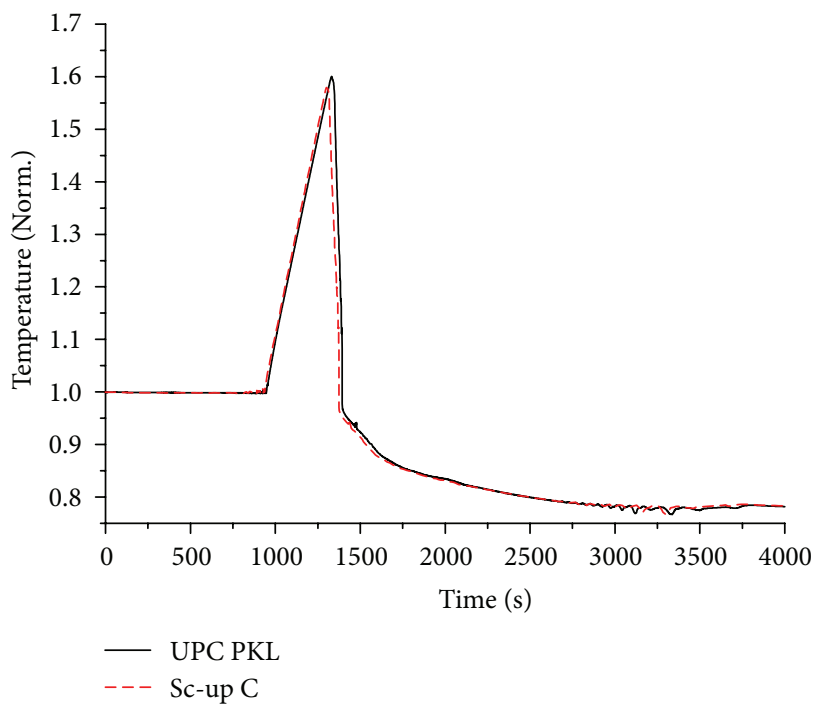

FIgure 29: Peak cladding temperature.

modified by adding the LSTF external heat losses, merging 4 loops into 2 loops, and adjusting the hot leg geometries in order to preserve the LSTF $L / \sqrt{D}$ factor and finally by removing the compensating heaters during the transient as in the LSTF conditions. The comparison between the 3 nodalizations shows that the external heat losses and the different hot leg geometries do not justify the delay between both nodalizations (see Figure 32).

For analyzing the discrepancy, components with different configuration that could affect the mass inventory and distribution have been studied. Those are as follows.

(i) Pressurizer and surge line: PKL surge line is not connected at the bottom of the pressurizer as in LSTF facility. During the blowdown, some water can remain stagnant below the connection anticipating the core dryout. 


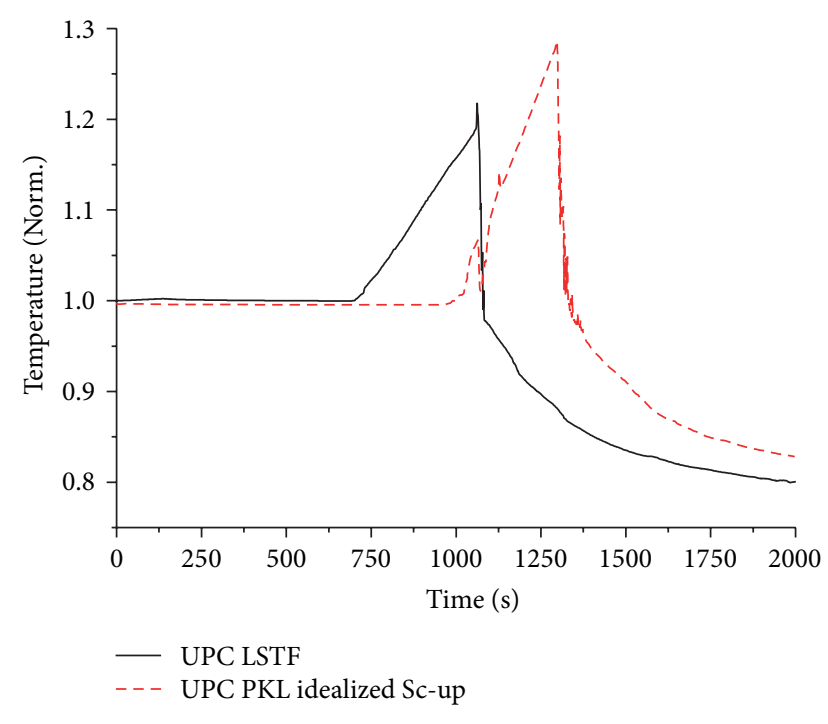

FIgURE 30: Core exit temperature.

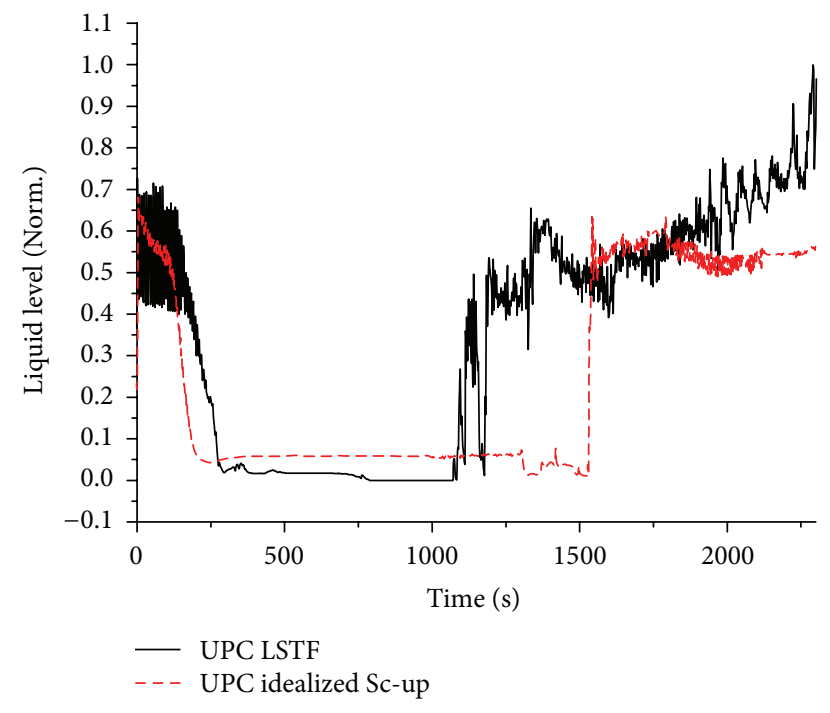

Figure 31: HL liquid level.

(ii) U-tube's surface: LSTF and PKL have different ratio between liquid volume and heat exchanging surface (LSTF U-tube surface $=1.01$ PKL U-tube surface) that could affect the reflux and condensation and the total amount of water in the primary side.

(iii) LSTF DC-to-HL bypass: LSTF has an external bypass not simulated in PKL which could imply different water distribution between hot legs and cold legs. It could modify break mass losses advancing or delaying core dryout.

(iv) Core passive heat structures: LSTF and PKL have different volume of core passive structures, which could affect the vapor generation and core liquid levels.

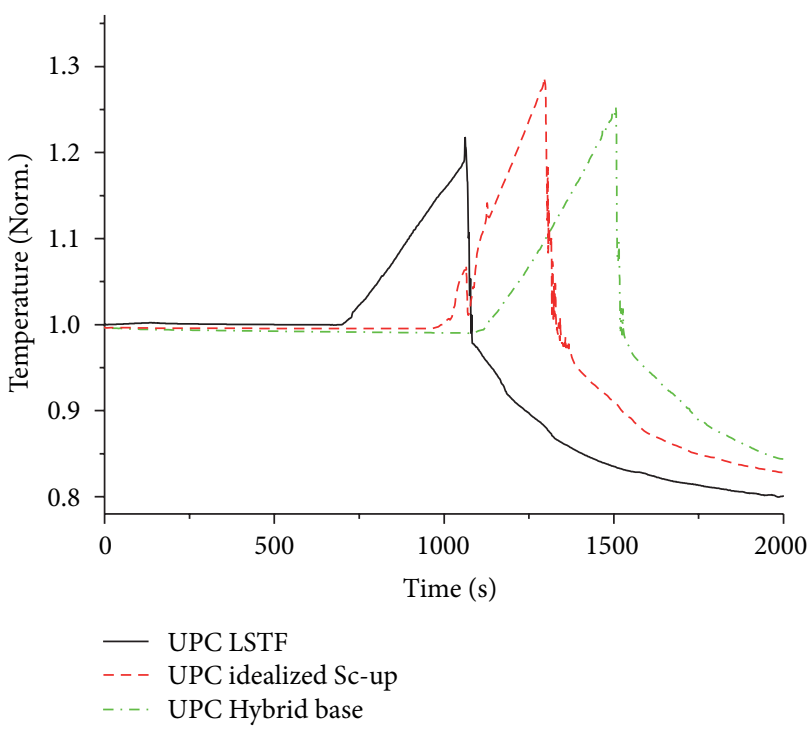

FIGURE 32: Core exit temperature.

Four hybrid nodalizations are performed in series adding one to one these LSTF components to the PKL hybrid base nodalization. The aim is to analyze, one by one and globally, how they modify the timing of the core dryout. The nodalizations are

(i) PKL Hybrid A nodalization: PKL Hybrid base nodalization + LSTF PZR;

(ii) PKL Hybrid B nodalization: PKL Hybrid A nodalization + LSTF U-tubes surface;

(iii) PKL Hybrid C nodalization: PKL Hybrid B nodalization + LSTF HL-to-DC bypass;

(iv) PKL Hybrid D nodalization: PKL Hybrid C nodalization + LSTF vessel passive HS.

The results of hot leg liquid levels and CET (Figures 33 and 34) show that there are no changes in the core dryout timing despite adding LSTF components to the PKL hybrid base nodalization. It demonstrates that these design differences do not have an effect on the reported discrepancy.

Finally, the vessel characteristics have been compared between both nodalizations, showing relevant differences in the configuration of the downcomer, the simulation of the core bypass flow path, and, specially, the amount of water between the bottom of the hot leg and the top of the core (these features are described in Table 7). Hence, a Hybrid E nodalization is generated adding to the "PKL Hybrid D nodalization" hydrodynamic components, HSs, and material properties of the LSTF vessel nodalization. The PKL fuel rods HSs are not modified. The results obtained with this new nodalization show that, for an identical amount of water in the hot legs at the beginning of the transient (for having the same PKL experimental initial conditions despite the changes in the nodalizations), the core dryout occurs at the same time as that of the LSTF posttest calculation just changing the water distribution of the PKL vessel with that of the LSTF vessel (see Figures 35 and 36). It demonstrates that delay 

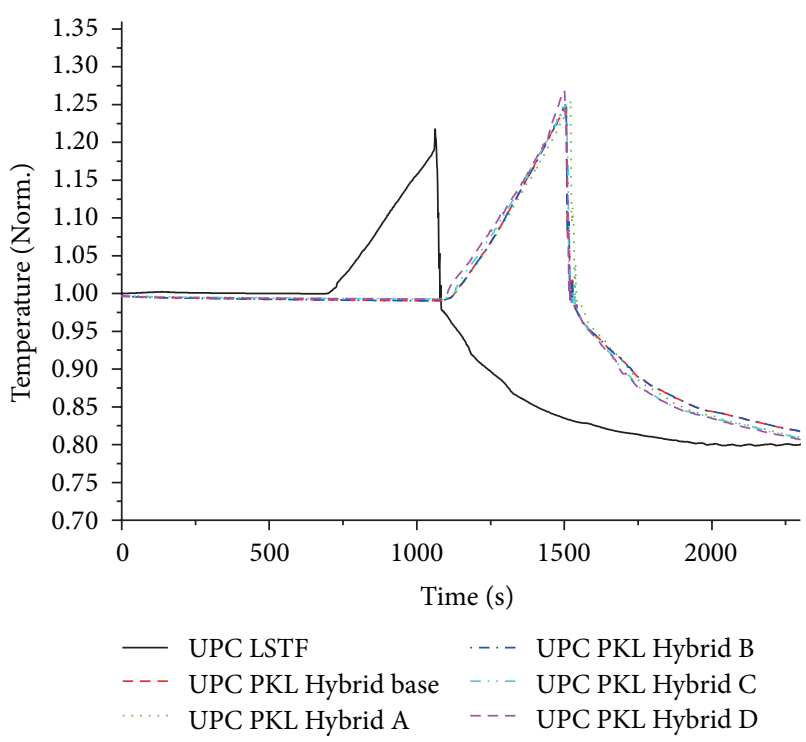

FIgURE 33: Core exit temperature.

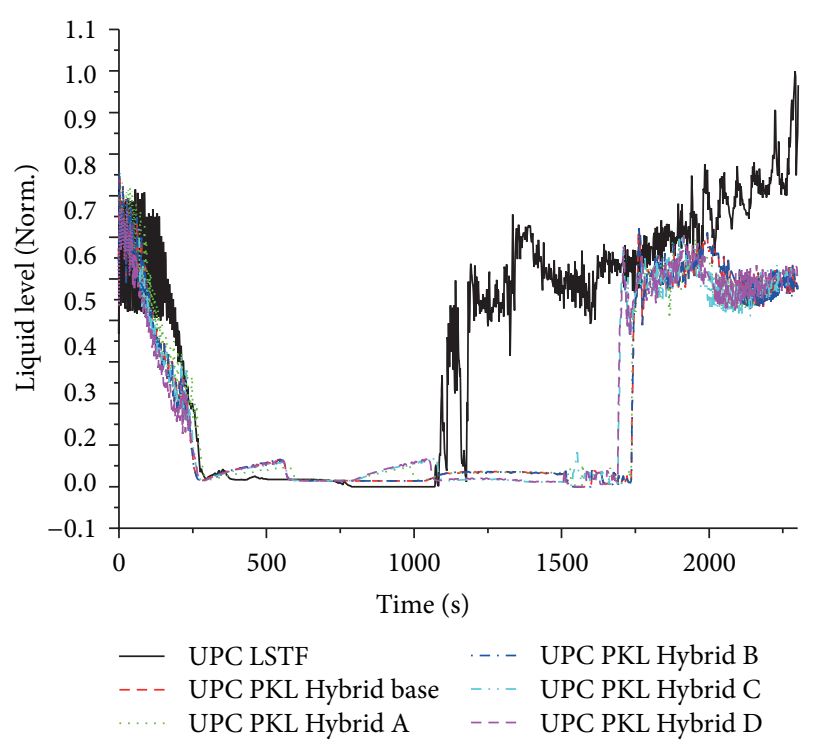

Figure 34: HL liquid level.

TABLE 7: LSTF and PKL vessel differences.

\begin{tabular}{lcc}
\hline & LSTF & PKL \\
\hline Downcomer & Annulus & 2 pipes \\
Core bypass & No & Yes \\
Mass inventory below hot leg & $\cong 0.75 \cdot$ MPKL & MPKL \\
\hline
\end{tabular}

between core dryout of both simulations is due to the different design of the vessel (KWU for PKL and Westinghouse for LSTF) and not for any scaling effect.

4.2.2. CET versus PCT Correlation. Major LSTF-PKL core design differences are shown in Table 8.

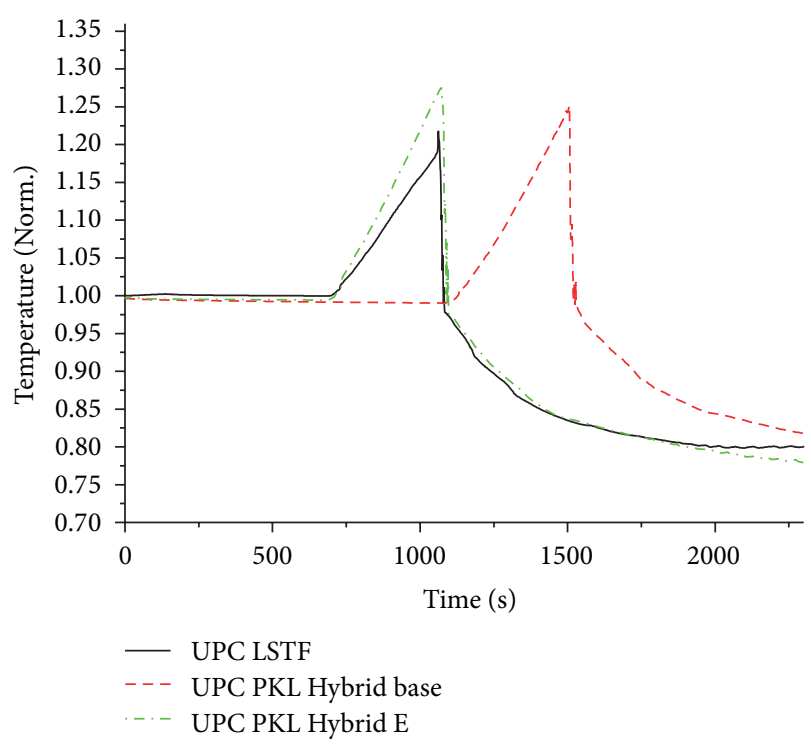

FIgURE 35: Core exit temperature.

TABLE 8: Core design differences.

\begin{tabular}{lcc}
\hline & LSTF & PKL \\
\hline Axial profile & Cosine & Flat \\
Radial profile & 3 & 1 \\
Fuel diameter $(\mathrm{mm})$ & 4.75 & 5.375 \\
Fuel height $(\mathrm{m})$ & 3.66 & 3.9 \\
Fuel surface $\left(\mathrm{m}^{2}\right)$ & 55.054 & $52.73(\cdot \mathrm{Kv})$ \\
Number of rods & 1008 & $801(\cdot \mathrm{Kv})$ \\
\hline
\end{tabular}

Two new PKL hybrid nodalizations are set up from the previous PKL Hybrid E nodalization in order to justify the discrepancy. Main characteristics are

(i) previous PKL Hybrid E nodalization:

(a) LSTF vessel HSs and hydrodynamic components,

(b) PKL fuel rods HSs,

(c) PKL fuel rods materials,

(d) PKL fuel rods profile (uniform);

(ii) PKL Hybrid F nodalization:

(a) PKL Hybrid E nodalization

(1) LSTF fuel rods HS's

(2) LSTF fuel rods materials;

(iii) PKL Hybrid G core nodalization:

(a) PKL Hybrid F nodalization

(1) LSTF fuel rods profile (cosine).

The comparison of the three hybrid nodalizations with both LSTF and PKL posttest calculations (Figure 37) demonstrate that the discrepancies in the slope of CET versus PCT 


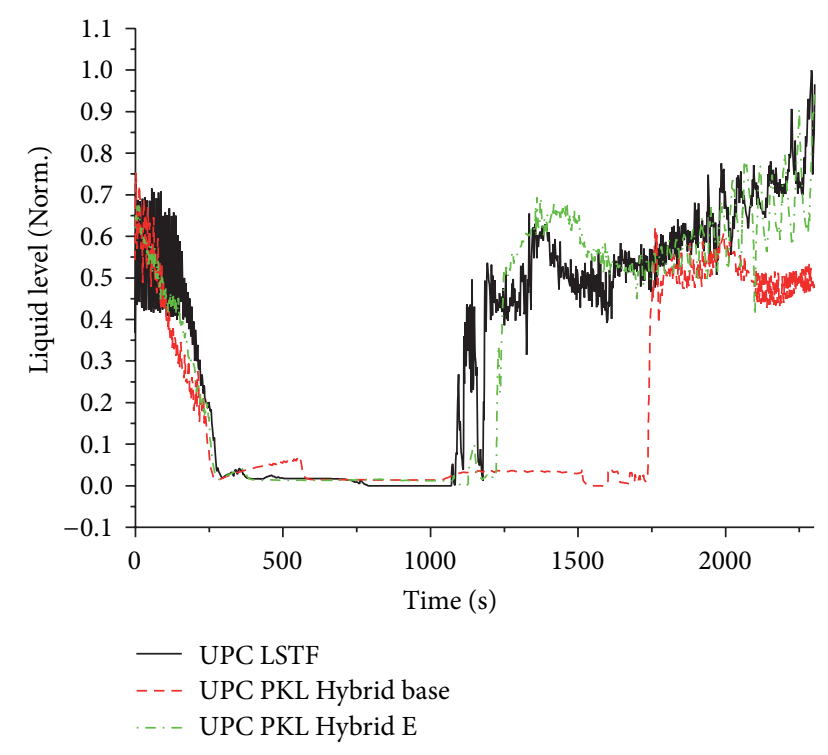

Figure 36: HL liquid level.

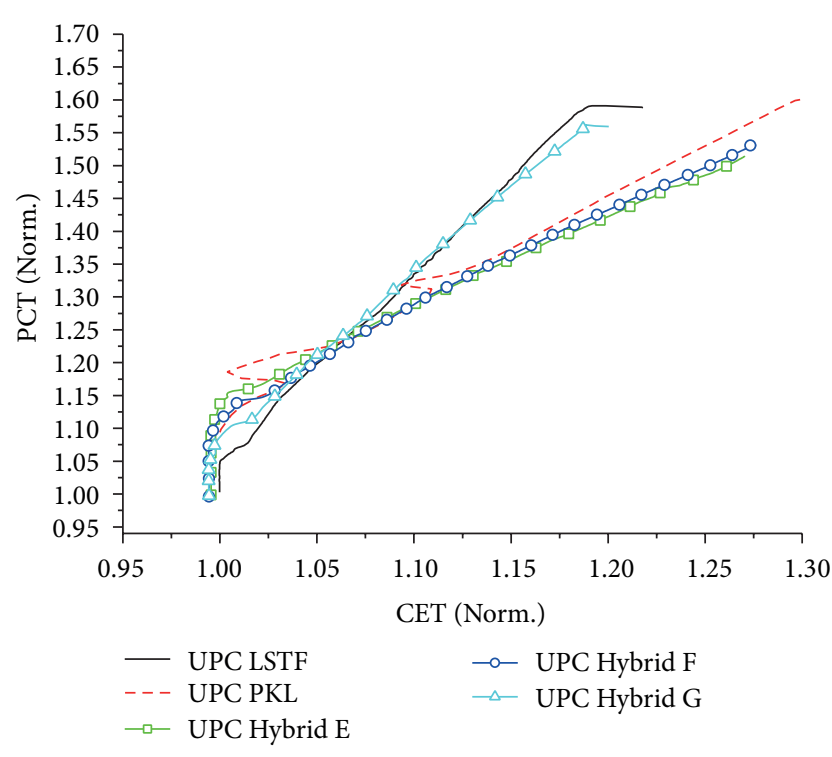

FIgure 37: PCT versus CET curve.

curves are mainly due to the different power distributions of PKL (uniform) and LSTF (cosine). As modifications between hybrid models have been implemented in a serial process, just when PKL core power profile is modified (PKL hybrid nodalization $G$ ), the slope of the curve becomes similar to the LSTF posttest CET versus PCT slope. On the other hand, previous changes (models $\mathrm{E}$ and $\mathrm{F}$ ) do not show significant modifications in the CET versus PCT correlation.

Finally, CET of the last nodalization (PKL Hybrid G nodalization) is compared (Figure 38) with the nodalization that justifies the delay in the core dryout (PKL Hybrid E nodalization). Results show that new modifications do not add distortion, justifying the consistency of the procedure.

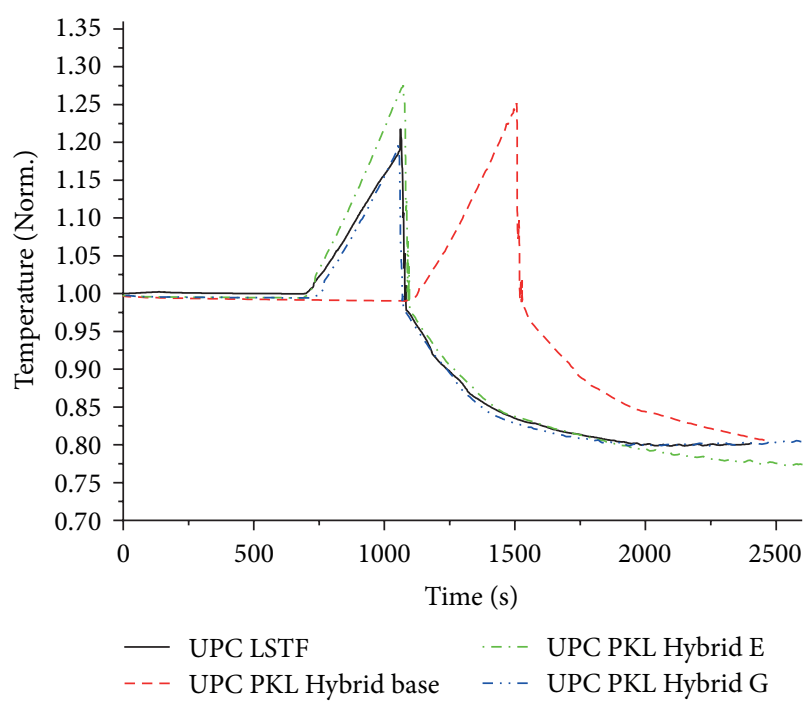

FIGURE 38: Core exit temperature.

\section{Conclusions}

The UPC scaling-up methodology has been applied for analyzing discrepancies that appear between the simulations of two counterpart tests. The conclusions related to the quality assurance of system codes modeling can be divided into two blocks, one related to the relevance of the ITF simulations and posttest analyses and the other one related to the guidelines of the proposed methodology for relating counterpart NPP scaled calculations (also known as $K_{v}$-scaled analysis; see [18]) and ITF posttest simulations.

In regard to the simulation of ITF tests, the present paper has demonstrated that posttest analyses and counterpart simulations are unavoidable in order to qualify the NPPs modeling criteria which the analyst applies for characterizing the NPP nodalization. Experimental data give the opportunity to improve ITF nodalizations for selected phenomena and scenarios, and, on the other hand, counterpart tests permit studying their consistency over different scales and designs. Only those phenomena that have been well reproduced using the same modeling criteria at different ITFs can be used for establishing modeling conclusions for qualifying and improving NPP nodalizations. About this point, the results of the present paper show how the LSTF-PKL counterpart tests have allowed the analyst to define which phenomena could be well reproduced by their nodalizations (CET versus PCT correlation) and which not (quenching during SG fast depressurization), in this way establishing the basis for a future extrapolation to an NPP scaled calculation.

In addition, the UPC scaling-up methodology has been checked over two counterpart simulations that were previously qualified with experimental data. The application of the scaling effect and design effect analysis described in [8] has demonstrated that selected phenomena can be perfectly scaled up between counterpart simulations by carefully considering the differences in scale and design. In relation 
to this, scaled-up and hybrid nodalizations can be used in order to scale results and predict the source of the possible discrepancies.

Future work will be devoted to show an application of the UPC scaled-up methodology for qualifying a commercial NPP nodalization over selected phenomena of LSTF-PKL counterpart tests.

\section{Nomenclature}

\begin{tabular}{|c|c|}
\hline 1D: & One-dimensional \\
\hline 3D: & Three-dimensional \\
\hline ACC: & Accumulator \\
\hline AM: & Accident management \\
\hline CET: & Core exit temperature \\
\hline CL: & Cold leg \\
\hline$D:$ & Pipe diameter \\
\hline DC: & Downcomer \\
\hline ECCS: & Emergency core coolant systems \\
\hline HL: & Hot leg \\
\hline HPI: & High-pressure injection \\
\hline HS: & Heat structure \\
\hline IAEA: & International Atomic Energy Agency \\
\hline ITF: & Integral test facility \\
\hline$K_{v}:$ & Scaling factor \\
\hline KWU: & Kraftwerk Union \\
\hline$L:$ & Length \\
\hline LOCA: & Loss-of-coolant accident \\
\hline LPSI: & Low-pressure safety injection \\
\hline LPI: & Low-pressure injection \\
\hline LSTF: & Large-Scale Test Facility \\
\hline NEA: & Nuclear energy agency \\
\hline NPP: & Nuclear power plant \\
\hline \multirow[t]{2}{*}{ OECD: } & Organization for Economic \\
\hline & Cooperation and Development \\
\hline PCT: & Peak cladding temperature \\
\hline PKL: & Primärkreislauf \\
\hline PtoV: & Power-to-volume \\
\hline PVST: & Power-to-volume scaling tool \\
\hline PZR: & Pressurizer \\
\hline $\mathrm{RC}:$ & Reflux condenser \\
\hline ROSA: & Rig of safety assessment \\
\hline SBLOCA: & Small break loss-of-coolant accident \\
\hline SG: & Steam generator \\
\hline$t:$ & Time \\
\hline UMAE: & $\begin{array}{l}\text { Uncertainty method based on accuracy } \\
\text { extrapolation }\end{array}$ \\
\hline UPC: & Universitat Politècnica de Catalunya \\
\hline USNRC: & United States Nuclear Regulatory \\
\hline & Commission \\
\hline VS: & Vapour superheating. \\
\hline
\end{tabular}

\section{Conflict of Interests}

The authors declare that there is no conflict of interests regarding the publication of this paper.

\section{Acknowledgments}

This paper contains findings that were produced within the OECD-NEA ROSA2 and OECD-NEA PKL2 projects. The authors are grateful to the Management Board of both projects for their consent to this paper. The authors also want to thank the Spanish Safety Council that has partially funded this research.

\section{References}

[1] "Accident analysis for nuclear power plants," Safety Reports Series 23, IAEA, Vienna, Austria, 2002.

[2] "Development and review of plant specific emergency operating procedures," Safety Reports Series 48, IAEA, Vienna, Austria, 2006.

[3] F. Reventos, "Thermal-hydraulic analysis tasks for ANAV NPPs in support of plant operation and control," Science and Technology of Nuclear Installations, vol. 2008, Article ID 153858, 13 pages, 2008.

[4] F. Reventós, C. Llopis, L. Batet, C. Pretel, and I. Sol, "Analysis of an actual reactor trip operating event due to a high variation of neutron flux occurring in the Vandells-II nuclear power plant," Nuclear Engineering and Design, vol. 240, no. 10, pp. 2999-3008, 2010.

[5] C. Llopis, F. Reventós, L. Batet, C. Pretel, and I. Sol, "Analysis of low load transients for the Vandellòs-II NPP. Application to operation and control support," Nuclear Engineering and Design, vol. 237, no. 18, pp. 2014-2023, 2007.

[6] F. Reventós, L. Batet, C. Llopis, C. Pretel, M. Salvat, and I. Sol, "Advanced qualification process of ANAV NPP integral dynamic models for supporting plant operation and control," Nuclear Engineering and Design, vol. 237, no. 1, pp. 54-63, 2007.

[7] A. Cuadra, J. Gago, and F. Reventos, "Analysis of a main steam line break in ascó nuclear power plant," Nuclear Technology, vol. 146, no. 1, pp. 41-48, 2004.

[8] V. Martinez-Quiroga and F. Reventos, "The use of system codes in scaling studies: relevant techniques for qualifying NPP nodalizations for particular scenarios," Science and Technology of Nuclear Installations, vol. 2014, Article ID 138745, 13 pages, 2014.

[9] H. Kremin, H. limprecht, R. Güneysu, and K. Umminger, "Description of the PKL III test facility," Framatome ANP Report, 2001.

[10] The ROSA-V Group, "ROSA-V Large Scale Test Facility (LSTF) system description for the third and fourth simulated fuel assemblies," Technical Report JAERI-Tech 2003-037, Japan Atomic Energy Agency, 2003.

[11] J. Freixa, F. Reventós, C. Pretel, L. Batet, and I. Sol, "SBLOCA with boron dilution in pressurized water reactors. Impact on operation and safety," Nuclear Engineering and Design, vol. 239, no. 4, pp. 749-760, 2009.

[12] J. Freixa, SBLOCA with boron dilution in pressurized water reactors. Impact to the operation and safety [Ph.D. thesis], Universitat Politècnica de Catalunya, DFEN, 2007.

[13] J. Freixa, F. Reventós, C. Pretel, and L. Batet, "Boron transport model with physical diffusion for RELAP5," Nuclear Technology, vol. 160, no. 2, pp. 205-215, 2007. 
[14] F. Reventós, J. Freixa, L. Batet et al., "An analytical comparative exercise on the OECD-SETH PKL E2.2 experiment," Nuclear Engineering and Design, vol. 238, no. 4, pp. 1146-1154, 2008.

[15] "RELAP5/MOD3 Code manual. Volume II: Appendix A Input Requirements," NUREG/CR-5535/Rev.1, ISL, Idaho, USA, January 2003.

[16] V. Martínez, F. Reventós, and C. Pretel, "Post-Test Calculation of the ROSA/LSTF Test 3-1 using RELAP5/mod3.3," NUREG/IA409, 2012.

[17] V. Martínez, F. Reventós, and C. Pretel, "Post-Test Calculation of the ROSA/LSTF Test 3-2 using RELAP5/mod3.3," NUREG/IA410, 2012.

[18] F. D’Auria and G. M. Galassi, "Scaling in nuclear reactor system thermal-hydraulics," Nuclear Engineering and Design, vol. 240, no. 10, pp. 3267-3293, 2010. 


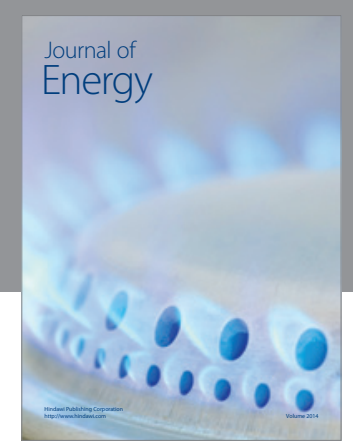

Journal of

Industrial Engineering
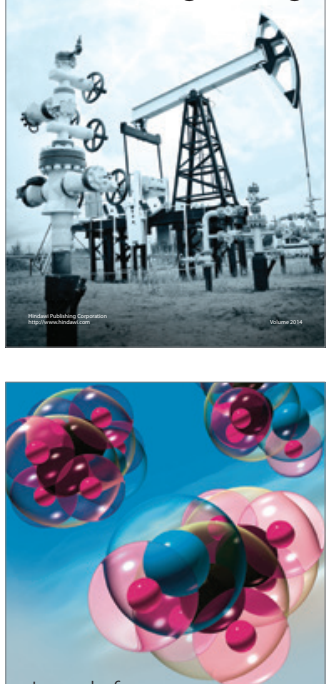

Fuels
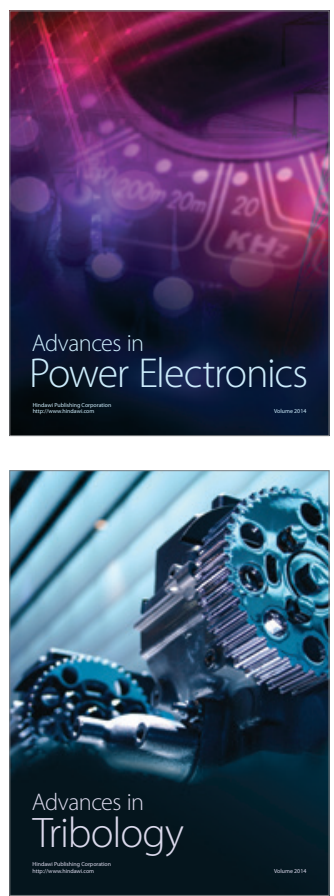

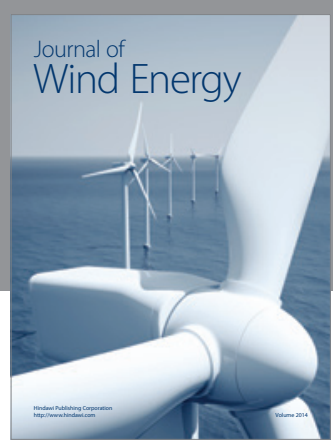

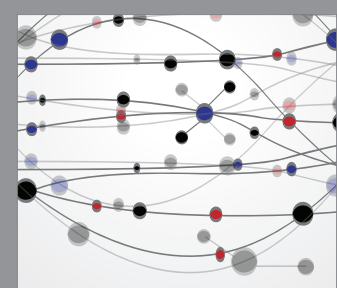

The Scientific World Journal

Submit your manuscripts at http://www.hindawi.com

Journal of

Structures
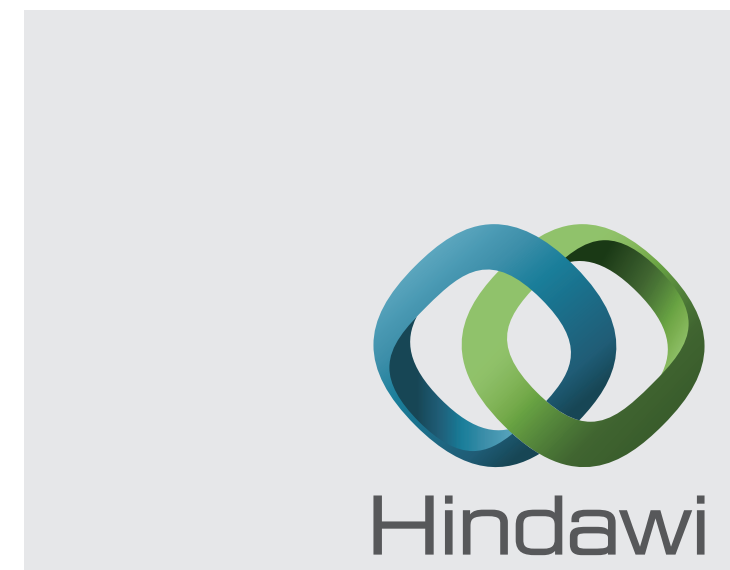

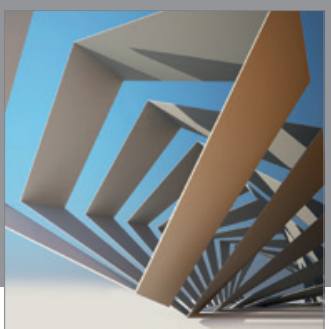

Rotating

Machinery
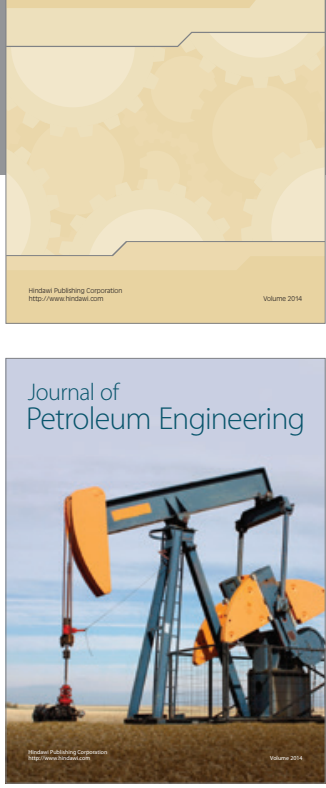

Journal of

Solar Energy
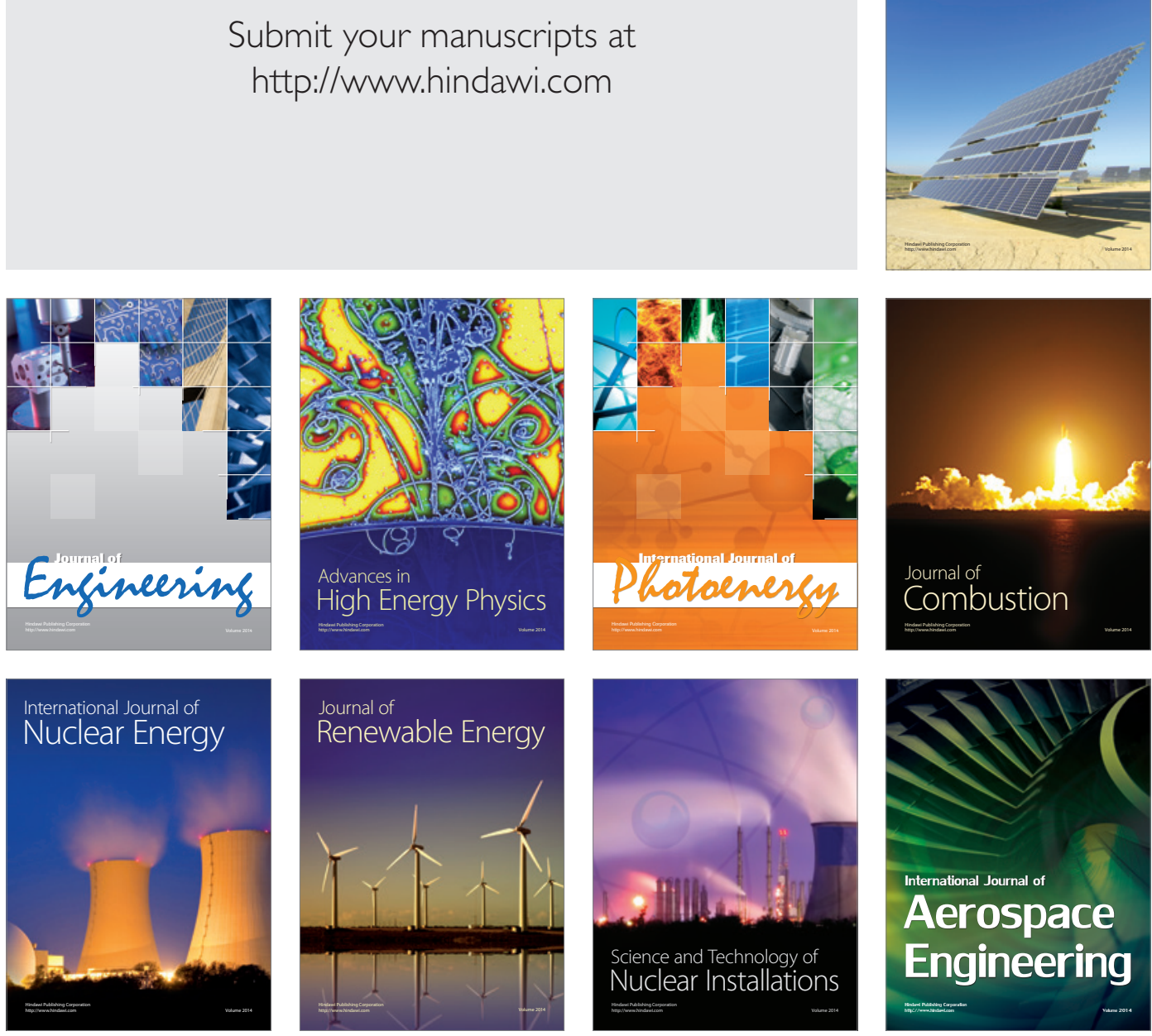